This item was submitted to Loughborough's Research Repository by the author.

Items in Figshare are protected by copyright, with all rights reserved, unless otherwise indicated.

\title{
Modelling cyclic moisture uptake in an epoxy adhesive
}

PLEASE CITE THE PUBLISHED VERSION

http://dx.doi.org/10.1080/00218460902997224

PUBLISHER

(c) Taylor and Francis

VERSION

AM (Accepted Manuscript)

LICENCE

CC BY-NC-ND 4.0

\section{REPOSITORY RECORD}

Mubashar, Aamir, lan A. Ashcroft, Gary W. Critchlow, and A.D. Crocombe. 2012. "Modelling Cyclic Moisture Uptake in an Epoxy Adhesive". figshare. https://hdl.handle.net/2134/9619. 
This item was submitted to Loughborough's Institutional Repository (https://dspace.lboro.ac.uk/) by the author and is made available under the following Creative Commons Licence conditions.

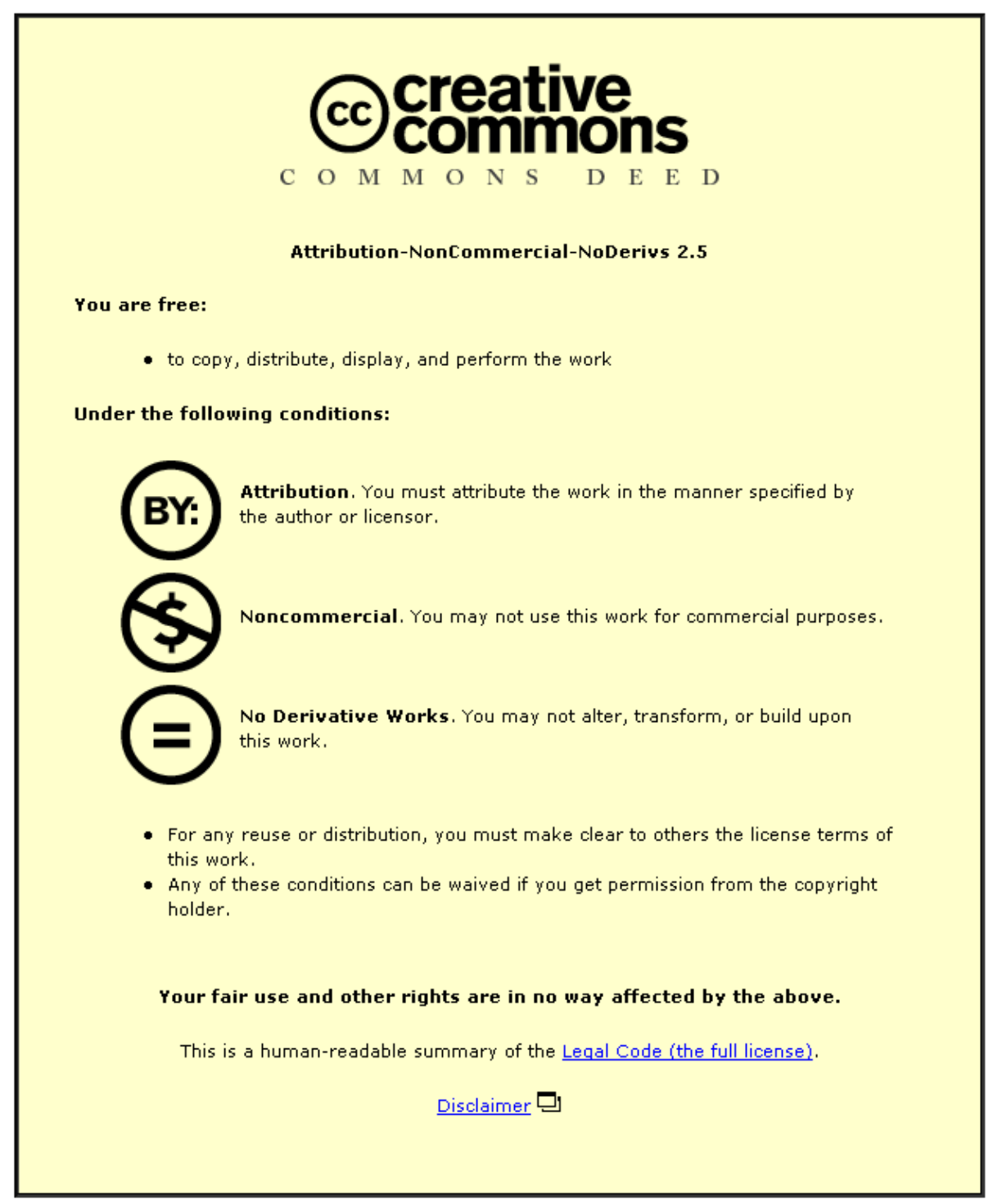

For the full text of this licence, please go to: http://creativecommons.org/licenses/by-nc-nd/2.5/ 


\title{
Modelling Cyclic Moisture Uptake in an Epoxy Adhesive
}

\author{
A. Mubashar ${ }^{a}$, I. A. Ashcroft ${ }^{a, *}$, G. W. Critchlow ${ }^{b}$, A. D. Crocombe \\ ${ }^{a}$ Wolfson School of Mechanical and Manufacturing Engineering, Loughborough University, \\ Loughborough, Leicestershire LE11 3TU, UK \\ ${ }^{b}$ Institute of Surface Science \& Technology, IPTME, Loughborough University, Loughborough, \\ Leicestershire LE11 3TU, UK \\ 'Division of Mechanical, Medical, and Aerospace, University of Surrey, Guildford GU2 7HX, UK
}

\section{Abstract}

This paper presents a methodology for predicting moisture concentration in an epoxy adhesive under cyclic moisture absorption-desorption conditions. The diffusion characteristics of the adhesive were determined by gravimetric experiments under cyclic moisture conditions and the dependence of diffusion coefficient and saturated mass uptake on moisture history was determined. Non-Fickian moisture absorption was observed during absorption cycles while moisture desorption remained Fickian. The diffusion coefficient and saturated moisture content showed variation with absorption-desorption cycling. A finite element based methodology incorporating moisture history was developed to predict the cyclic moisture concentration. A comparison is made between the new modelling methodology and a similar method that neglects the moisture history dependence. It was seen that the concentration predictions based on non-history dependent diffusion characteristics resulted in over-prediction of the moisture concentration in cyclic conditioning of adhesive joints. The proposed method serves as the first step in the formulation of a general methodology to predict the moisture dependent degradation and failure in adhesives.

Keywords: Cyclic moisture diffusion, Epoxy Adhesive, Finite Element User Models.

* Corresponding author. Tel: +44 1509 223229; fax: +44 1509223934

Email address: i.a.ashcroft@lboro.ac.uk(I.A.Ashcroft) 


\section{Introduction}

Adhesive joining is an attractive alternative to conventional joining methods, such as welding and mechanical fasteners, especially in the aerospace and automobile industries. The benefits of adhesive bonding include: the ability to form lightweight; high stiffness structures; joining of different types of materials; better fatigue performance, and reduction in the stress concentrations observed with mechanical fasteners or the effects on the adherend of the heat associated with welding. However, concerns about the durability of adhesive joints still hinders their widespread use in structural applications. Moisture has been identified as one of the major factors affecting joint durability. This is especially important in applications where joints are exposed to varying moisture conditions throughout their useful life. Moisture has an adverse effect on adhesive strength, which decreases with increasing moisture content $[1,2]$. Plasticisation and swelling of adhesives occur with moisture diffusion and are among the major factors considered responsible for the changes in strength [3].

Fickian diffusion has been used by researchers to predict moisture concentration in adhesives $[4,5]$. In Fickian diffusion it is assumed that the moisture flux is directly proportional to the concentration gradient in a material and thus the concentration of moisture at a point in a plane sheet of thickness $2 l$ may be determined by

$$
C_{t}=\left(1-\frac{4}{\pi} \sum_{n=0}^{\infty} \frac{-1}{2 n+1} e^{\frac{-D 2 n+1^{2} \pi^{2} t}{4 l^{2}}} \cos \frac{2 n+1 \pi x}{2 l}\right) \times C_{\infty}
$$

where $C_{t}$ is moisture concentration at any time interval $t, C_{\infty}$ is the saturated moisture concentration, $D$ is the diffusion coefficient and $x$ is the spatial coordinate. The mass uptake $M_{t}$ at any time interval $t$, obtained by integrating Equation (1) over the domain, is given by 


$$
M_{t}=\left(1-\frac{8}{\pi^{2}} \sum_{n=0}^{\infty} \frac{1}{2 n+1^{2}} e^{\frac{-D 2 n+1^{2} \pi^{2} t}{4 l^{2}}}\right) \times M_{\infty}
$$

Fickian diffusion is observed in polymers well above the glass transition temperature $\left(\mathrm{T}_{\mathrm{g}}\right)[6]$. At temperatures below $T_{g}$, a non-Fickian moisture uptake is observed, where the diffusion process deviates from Fickian behaviour after initial uptake. Several models have been suggested to predict non-Fickian uptake behaviour [7-10] including a dual Fickian model, which is based on two Fickian processes [11]. The two mechanisms of the dual Fickian model are considered to be working in parallel, where the concentration at any point may be determined by

$$
\begin{aligned}
& C_{t}=\left(1-\frac{4}{\pi} \sum_{n=0}^{\infty} \frac{-1}{2 n+1} e^{\frac{-D_{1} 2 n+1^{2} \pi^{2} t}{4 l^{2}}} \cos \frac{2 n+1 \pi x}{2 l}\right) \times C_{1 \infty}+ \\
& \left(1-\frac{4}{\pi} \sum_{n=0}^{\infty} \frac{-1}{2 n+1} e^{\frac{-D_{2} 2 n+1^{2} \pi^{2} t}{4 l^{2}}} \cos \frac{2 n+1 \pi x}{2 l}\right) \times C_{2 \infty}
\end{aligned}
$$

where $C_{1 \infty}$ and $C_{2 \infty}$ are the saturated concentrations, $D_{1}$ and $D_{2}$ are the diffusion coefficients and $l$ is the length of the diffusion path. The mass uptake for the dual Fickian model at any time $t$ is given by

$$
M_{t}=\left(1-\frac{8}{\pi^{2}} \sum_{n=0}^{\infty} \frac{1}{2 n+1^{2}} e^{\frac{-D_{1} 2 n+1^{2} \pi^{2} t}{4 l^{2}}}\right) \times M_{1 \infty}+\left(1-\frac{8}{\pi^{2}} \sum_{n=0}^{\infty} \frac{1}{2 n+1^{2}} e^{\frac{-D_{2} 2 n+1^{2} \pi^{2} t}{4 l^{2}}}\right) \times M_{2 \infty}
$$

where $M_{1 \infty}$ and $M_{2 \infty}$ are the saturated masses and the sum of $M_{1 \infty}$ and $M_{2 \infty}$ gives the total saturated mass.

Diffusion coefficient, $D$, and saturated moisture content, $M_{\infty}$ are frequently determined using a single experimental moisture uptake curve $[9,12,13]$. However, it has been observed that 
the diffusion in a polymer is dependent on hygroscopic history. Lin and Chen [14] studied the moisture diffusion characteristics of a DGEBA/DDA epoxy system by exposing it to a sorption-desorption-resorption cycle. The desorption and second absorption were faster than the original absorption, showing an increase in the diffusion coefficient. Also the equilibrium water content of the resorption process was greater than the sorption process. This indicated that the material properties changed with moisture cycling. In service environments, where adhesives are subjected to significant changes in humidity, the hygroscopic history has to be considered in order to accurately determine the moisture concentration. This is necessary as it provides the basis for the determination of hygroscopic stresses, strength degradation and failure and thus should be incorporated in predictive modelling methods. However, few attempts have been made to study the diffusion characteristics of an adhesive under cyclic environmental conditions and hence predictive models currently neglect moisture history effects.

The work presented in this paper characterises the diffusion behaviour of an epoxy adhesive over multiple absorption-desorption cycles. The dependence of $D$ and $M_{\infty}$ on cyclic moisture diffusion are studied by experimentation and a model is proposed to predict diffusion over multiple cycles. In the second part of the paper, a finite element (FE) approach is used to introduce a methodology for the prediction of moisture concentration based on cyclic moisture dependent diffusion parameters. A comparison of the developed methodology with a similar FE method in which moisture history is neglected is presented, where both methods are used to predict the water concentration in a single lap joint exposed to cyclic humidity conditions. This work serves as a first, and necessary step, in the development of a cyclic aging strength prediction methodology. 


\section{Characterisation of Cyclic Moisture Uptake}

The history dependent moisture sorption properties of a rubber toughened epoxy adhesive were determined experimentally. The adhesive used was FM73-M, supplied by Cytec Engineered Materials and comes with a polyester knitted carrier for support and handling purposes.

Before preparation of the bulk samples, the adhesive was brought to room temperature, in a desiccator, from its storage temperature of $-24^{\circ} \mathrm{C}$. Bulk samples of $1 \mathrm{~mm}$ thickness were prepared by stacking multiple layers of the adhesive film, each of $0.12 \mathrm{~mm}$ thickness. During manufacture, the layers were compressed using a steel roller to ensure that air trapped between the layers was released as this helps to minimise the formation of voids during curing. The adhesive layup was placed in a mould and cured in a hot press at $120^{\circ} \mathrm{C}$ for one hour [15]. The bulk samples of dimensions $60 \times 40$ x $1 \mathrm{~mm}$ were cut from the cured layup.

The moisture diffusion properties of the adhesive were determined by the gravimetric method using the procedures and guidelines in [16]. Before commencing the environmental conditioning, the bulk samples were dried in an oven at $50^{\circ} \mathrm{C}$ to constant weight. Two sets of three samples were conditioned at $50^{\circ} \mathrm{C}$, immersed in deionised water. This temperature is well below the glass transition temperature of the adhesive, which has been reported to be $99.7^{\circ} \mathrm{C}$ when cured at $120^{\circ} \mathrm{C}$ for one hour [17]. The samples were subjected to three absorption-desorption cycles. A Mettler Toledo AL204 electronic balance with $0.1 \mathrm{mg}$ accuracy was used to weigh the samples at predetermined time intervals during conditioning.

The percentage moisture content in the bulk adhesive, $m_{t}$, at any time $t$ is given by

$$
m_{t}=\frac{m_{2}-m_{1}}{m_{1}} \times 100
$$


where $m_{1}$ is the mass of the specimen after initial drying and before immersion and $m_{2}$ is the mass of the specimen at a specified time, $t$.

\section{Experimental Results}

Figure 1 shows the average percentage mass uptake as a function of $\sqrt{t} / l$ from the absorption and desorption experiments. Repeatability of the tests was good with a standard deviation of 0.11. Considering the first moisture uptake, the rate of absorption is faster during the initial stages of diffusion. At later stages, the absorption deviates from the initial uptake trend and follows a different gradient. The overall diffusion coefficient does not remain constant and changes with increasing concentration. After reaching an apparent equilibrium, the first absorption plot shows a sudden increase in mass uptake at $\sqrt{t} / l$ of approximately 28 $\sqrt{ } \mathrm{hr} / \mathrm{mm}$. Similar behaviour has been reported previously [18] and may be due to leeching of the adhesive during conditioning. The chemical composition of the polymer has a strong impact on the diffusion properties. Hygroscopic polymers such as epoxies have polar groups with strong affinity for water molecules and the significant interaction between the moisture and the polymer can result in a high dependence of $D$ on concentration. It is clear from the experimental observations that a Fickian diffusion based absorption model is inadequate in explaining the moisture uptake.

In the first desorption, diffusion takes place until a constant weight is achieved as in a Fickian diffusion process. The desorption process is clearly not the reverse of the absorption process. This is seen more clearly in Figure 1(b) in which nominal mass uptake is used and the desorption plots are included to allow direct comparison with the absorption plots. These results indicate a physical change in the polymer structure during absorption. A constant $D$ Fickian diffusion indicates that free water removal was the major process in desorption. It was also noted that the bulk adhesive samples achieved their original weight after desorption 
and the desorption process was faster than the absorption, which is a further indication of changing adhesive structure due to moisture ingress.

Full saturation was not achieved during absorptions as the samples were conditioned for a predetermined time. $\mathrm{M}_{\infty}$ and $D$ were estimated by least square fitting of a dual Fickian model to the experimental data. The curve fitting was carried out in MathCAD using the genfit function, which employs an optimised Levenberg-Marquardt method [19]. The results of the dual Fickian curve fits are plotted in Figure 2a and the coefficients of the dual Fickian model are given in Table 1. Although the dual Fickian model did not provide an exact curve fit to the first absorption due to the presence of the secondary uptake, the fit is considered adequate as the model provides a reasonable prediction of the initial and final uptake and the secondary uptake requires further study. Moreover the dual Fickian model provides an excellent fit to the resorption plots. The desorption process was modelled using Fickian diffusion and it is seen in Figure $2 b$ that this provides a good fit to the desorption plots. The coefficients of the Fickian model are given in Table 2.

Summarising the absorption-desorption cycling, the absorption exhibits non-Fickian behaviour while desorption follow Fickian diffusion. The secondary uptake behaviour observed during the first absorption was not observed in further absorption cycles. The absorption-desorption cycling caused an increase in $D$ and $M_{\infty}$. In the dual Fickian model, $D_{1}$ increased most between the first and second absorptions while $D_{2}$ showed a more linear increase over the absorption cycles, as shown in Figure 3(a) and Figure 3(b) where $D_{o}$ is the absorption or desorption coefficient during first cycle. The desorption diffusion coefficient, $D_{d}$, which was determined based on a Fickian diffusion model, increased more during the second and third cycle than first and second cycle as can be seen in Figure 3(c), $M_{\infty}$ increased slightly during moisture cycling as shown in Figure 3(d). 
The diffusion parameters along with the cyclic moisture dependent properties were used to develop a new methodology for determining the moisture concentration under cyclic humidity conditions, which is presented in the next section.

\section{Prediction of Cyclic Moisture Diffusion}

\subsection{Finite Element Approach}

The finite element method (FEM) provides a means of predicting moisture concentration in complex geometries with variable boundary conditions and allows coupling with a mechanical analysis incorporating damage and failure predictive models [20-22]. FEM is capable of modelling transient moisture diffusion but many of the commercial software packages lack a built-in capability for modelling moisture diffusion or have limited implementations. The alternative is to use a direct analogy between conduction heat transfer and moisture diffusion [23]. Diffusion is governed by Fick's first and second laws, which are given in Equation (6) and (7).

$$
\begin{gathered}
F=-D \frac{\partial C}{\partial x} \\
\frac{\partial C}{\partial t}=D \frac{\partial^{2} C}{\partial x^{2}}
\end{gathered}
$$

where $F$ is the flux, $D$ is diffusion coefficient, $C$ is concentration and $t$ is time. The corresponding heat transfer equations are given in Equation (8) and (9).

$$
\begin{gathered}
F=-k \frac{\partial T}{\partial x} \\
\frac{\partial T}{\partial t}=\left(\frac{k}{c \rho}\right) \frac{\partial^{2} T}{\partial x^{2}}
\end{gathered}
$$


where $T$ is temperature, $k$ is thermal conductivity, $\rho$ is density, and $c$ is the specific heat. By comparing the above equations, diffusion may be modelled by equating $D$ with $k$ and $C$ with $T$. The $\rho$ and $c$ may be taken as unity for a system with a single material.

In order to incorporate the cyclic moisture dependency in a predictive model, the empirical relationships of $D$ and $M_{\infty}$ with the number of diffusion cycles, $n$, were determined by least squares curve fitting. As before, the curve fitting was carried out in MathCAD and the results are shown in Figure 3. The form of functions used for curve fitting of $D_{1}, D_{d}, M_{\infty}$ is given in Equation (10) and that for $D_{2}$ is given in Equation (11).

$$
\begin{gathered}
a n^{b}+c \\
x e^{y n}
\end{gathered}
$$

where $a, b, c, x$ and $y$ are constants obtained by curve fitting and given in Table 3 .

The overall methodology for predicting cyclic moisture diffusion is illustrated in Figure 4. The FE model is assigned history dependent diffusion properties determined by experimentation. Since in-built material models are not adequate for this purpose, a user subroutine was implemented, which is described in the next section. The dual Fickian diffusion may be determined by post processing the results of two Fickian diffusion models. In the case of multiple cycles, the moisture history and state of material from one analysis is transferred to the next analysis by post processing routines and the analysis may continue for any number of cycles. The detailed implementation of the user subroutine is discussed in the next section. 


\subsection{Cyclic Moisture Dependent Predictive Model}

The cyclic moisture dependent model was implemented in the commercial finite element code ABAQUS. Subroutine, UMATHT, is available in ABAQUS for introducing a user defined material and was used to implement the moisture history dependence. The structure of the subroutine is illustrated by the flow chart in Figure 5. The moisture history of the adhesive was maintained during the analysis by the use of scalar internal state variables, denoted by SV. Three state variables were used; the first state variable stores the moisture history in the form of absorption-desorption cycles. The second variable stores the nature of the diffusion process, i.e. absorption or desorption, while the third state variable records the amount of moisture diffused during a single absorption or desorption.

The moisture cycling is based on a minimum amount of moisture absorbed in the adhesive that would change the diffusion characteristics of the adhesive. The critical concentration is an input parameter to the user subroutine, which is used to avoid minute fluctuations in moisture concentration when determining completion of a diffusion cycle. As the boundary conditions are changed, small changes in concentration may occur causing the user subroutine to determine many diffusion cycles. Thus an absorption-desorption cycle is established when the moisture concentration at a point in the adhesive exceeds a critical concentration upon change of boundary conditions. The internal state variables were implemented as solution dependent variables.

The history dependence of diffusion characteristics is incorporated by using the relationships developed in Section 3. The user subroutine uses a flag variable (FV) to determine the appropriate diffusion coefficients in the case of dual Fickian diffusion, where two parallel Fickian models were used to obtain the total moisture diffusion. The moisture history is 
transferred between sequential analyses by using a Python script and the SDVINI subroutine. SDVINI is an ABAQUS subroutine for initiating state variables.

\section{Comparison of Moisture Prediction Methodologies}

In this section, two cases of multiple absorption-desorption in an adhesive joint are considered in order to illustrate the effect of including the cyclic moisture absorption on the prediction of moisture concentration. In the first case, the diffusion parameters are based on a single absorption curve while diffusion parameters determined from multiple absorptiondesorption cycles are used in the second case, which incorporates the effects of the changes in $D$ and $M_{\infty}$ during cyclic diffusion. The history dependence of diffusion parameters is implemented via the developed user subroutines.

A single lap joint was modelled with aluminium adherends bonded by adhesive FM73. Diffusion was assumed to be taking place through the bulk adhesive only i.e. no interfacial diffusion was considered. Using symmetry, only one quarter of the adhesive layer was modelled. The adherends, as non-absorbing, did not need to be explicitly included in the model and are represented only by insolubility boundary condition. Fillets were also not included in the model as they would not affect the comparative study. The boundary conditions were applied in the form of normalised moisture concentration and specific boundary conditions for each case are discussed later. A refined mesh with $0.3 \times 0.3 \mathrm{~mm}$ four node, linear 2D quadrilateral heat transfer field elements was used. Figure 6 illustrates the geometry of the single lap joint and the meshing of the adhesive layer.

Four cyclic conditioning environments, with absorption or desorption times of 300, 600, 1200 and $2400 \mathrm{hrs}$, were considered and each conditioning environment consisted of three absorption-desorption cycles. A typical multi-cycle conditioning environment is shown in Figure 7, in this case with absorption and desorption cycles of $2400 \mathrm{hrs}$. 


\subsection{Case I: Predictive Modelling Using Diffusion Parameters Based on a Single Moisture Uptake Curve}

The diffusion coefficients determined by curve fitting a dual Fickian diffusion model to the first experimental absorption data, were used to predict concentration in the adhesive layer after multiple absorption cycles. The boundary conditions were applied in the form of normalised moisture concentration $C / C_{\infty}$. The dual Fickian model was implemented by running two sequential analyses with $D=D_{1}$ and $D=D_{2}$ and a script was used to add the concentration at each integration point, providing the dual Fickian moisture uptake. The absorption cycles were followed by desorption cycles, which were based on a Fickian diffusion model. The first diffusion coefficient obtained for the dual Fickian model, $D_{1}$, was used to predict the desorption. The concentration predicted in the first step was used as the initial concentration for the next analysis step. The analysis continued until the completion of the required environmental cycling.

Figure 8 compares concentration profiles after the first absorption for the four conditioning environments, the plots showing concentration at the centre of the adhesive layer (as illustrated in Figure 6). It can be seen that the amount of absorbed moisture increases with absorption time, however, saturation is still not reached even after $2400 \mathrm{hrs}$ of absorption. Figure 9 plots the moisture concentration in the adhesive layer after the first desorption cycle and shows that some moisture remains in the adhesive layer at the end of the desorption for all cycle times. The amount of moisture is a maximum at the centre of the overlap except for the desorption cycle of $300 \mathrm{hrs}$. The diffusion process is governed by the moisture activity in the adhesive layer. At the start of the desorption, there is a high concentration gradient in areas close to the edges of the joint because saturation was not achieved during the previous absorption. This drives diffusion towards the centre of the overlap, in addition to the drive for 
diffusion towards the edges of the adhesive caused by the introduction of the "dry" boundary condition. Thus during the initial stages of the desorption, both absorption and desorption processes are occurring simultaneously in different areas of the adhesive layer. Desorption from the overlap centre starts only after a higher concentration in the surrounding material is achieved. Owing to this simultaneous absorption and desorption different parts of the adhesive may be subjected to different diffusion rates. Figure 10 shows a typical desorption process where the adhesive layer is not fully saturated at the start of the desorption. As desorption cycle starts, diffusion to the middle of the adhesive layer continues from the surrounding high concentration areas. This continues until the centre of the adhesive layer achieves a higher concentration than the surrounding material because of moisture transport towards both the edges and centre from this region.

The experimental results, as shown in Figure 1, showed that desorption was faster than absorption and thus the residual moisture predicted in the adhesive layer using an absorption based diffusion coefficient will tend to result in an over-prediction of the moisture concentration. Figure 11 compares the moisture concentration in the adhesive layer after repeated cycles of $1200 \mathrm{hrs}$ and it can be seen that the moisture concentration increases with each absorption cycle. As the $D$ and $M_{\infty}$ remain constant between diffusion cycles, the increase in moisture concentration can be attributed to the residual moisture left in the adhesive after each desorption process. The amount of residual moisture also increased after each desorption as the moisture accumulated over desorption cycles, however, the increase in residual moisture becomes less with increasing number of cycles. The increase in residual moisture can be attributed to the fact that the adhesive layer did not achieve saturation during absorption and moisture flowed towards the centre of the adhesive layer from surrounding areas during subsequent cycles. The residual moisture in the adhesive layer is reduced when the cycle time is increased to $2400 \mathrm{hrs}$, as shown in Figure 12. Owing to the increased 
absorption time, less residual moisture is predicted in the adhesive layer during each desorption of $2400 \mathrm{hrs}$. As water distribution in the adhesive layer is more homogeneous than with the 1200 hrs cycles, the difference between residual moisture at the centre of adhesive layer after repeated cycles is greatly reduced.

\subsection{Case II: Predictive Modelling Using Diffusion Parameters Based on Multiple Diffusion Cycles}

To demonstrate the effects of history dependent diffusion characteristics on moisture concentration prediction, the modelling methodology described in Section 4.2 was applied to a single lap joint subjected to the same environmental conditions as that for Case I in Section

5.1. Figure 13 compares the concentration profiles at the middle of the adhesive layer for the 1200 hrs cyclic conditioning environment. The predicted concentration after the first absorption processes is similar for both Case I and II, as seen by comparing Figures 11 and 13, since the diffusion coefficients are the same for the first absorption. However, because of the faster desorption, the amount of residual moisture after the first desorption is less in Case II than in Case I. The moisture concentration after the second absorption was higher in Case II even though the amount of the residual moisture was less at the start of the absorption than in Case I. This was because of the effect of using moisture dependent absorption coefficients. The third absorption, in Case II, predicted a lower moisture concentration than in the Case I and the amount of residual moisture decreases over multiple desorption processes as the history dependent $D$ increases.

In the case of $2400 \mathrm{hr}$ cycles, the moisture concentration in the first absorption is the same in both cases, as may be seen in Figures 12 and 14. In the second absorption, higher moisture concentration is predicted in Case II than in Case I, which is consistent with the predictions with the $1200 \mathrm{hr}$ cycles. However, the moisture absorption predicted after the third absorption 
is also higher in Case II than in Case I, which is the opposite to that seen with $1200 \mathrm{hr}$ cycles. The residual moisture after each desorption is also lower in Case II than Case I. The longer cycles also result in lower residual moisture at the end of the desorption cycles.

\section{Discussion}

Moisture cycling affects polymers in several ways including; the increased free volume due to swelling [14], the reaction of water with the polymer, leaching of material, micro-cracking and the progressive damage mechanisms. Carter and Kibler [24] suggested that water in a polymer can exist in free or bound states. If there are chemical reactions between the polymer and the water, the water becomes attached to the polymer and is not free to move, whereas, the water present in the free volume of the polymer is free to move. The free volume exists in a polymer due to the gaps between the polymer chains and depends on the density and physical state of the polymer. The diffusion of water in a polymer depends on the available free volume within the polymer, a higher free volume results in a higher capacity for absorption of water. A Langmuir type model was suggested by Carter and Kibler to predict the moisture concentration, which has additional parameters to those used in Fickian diffusion; the probability that bound water may be released and the probability that free water may become bound. It has also been suggested that during initial moisture uptake, the moisture enters the free volume of the polymer, which does not cause swelling of the polymer [25]. During later stages, when most of the free volume is filled, the absorbed moisture distorts the polymer network and causes swelling. As the polymer swells, additional free volume may become available for diffused water.

It may be seen from Figure 3 that the absorption-desorption cycles affect $D$ and $M_{\infty}$ in a different manner. The rapid initial uptake of water by the adhesive and consequently the 
higher $D_{1}$ than $D_{2}$ may occur as the water initially fills up the free volume of the adhesive. However, as the free volume no longer remains available, swelling of the adhesive starts to take place and a lower value of $D$ is observed. Owing to the interaction of water and adhesive, more sites for reaction of water will become available. During the desorption, a Fickian diffusion curve indicates that free water diffusion is the predominant process.

Comparison of the modelling methodologies where the effect of hygroscopic history is ignored (Case I) and included (Case II) show that the predicted moisture concentrations were different in both cases. This is true for absorption as well as desorption cycles. The predicted concentration after absorption in Case II has no clear relation with that of Case I, as shown in Figure 15(a) and (b). Case I predicted higher concentration than Case II after the third absorption for $1200 \mathrm{hr}$ cycles while Case II predicted higher concentration for $2400 \mathrm{hr}$ cycles. Thus the amount of moisture in the adhesive layer, along with history dependent diffusion coefficients present a unique diffusion situation in each absorption cycle, which is difficult to predict based on a general pattern.

In general, the desorption cycles in Case II predicted a lower residual moisture at the end of each cycle than Case I, as can be seen in Figure 16(a) and (b). This is the result of the use of moisture dependent diffusion coefficients, which increase with each desorption cycle. The lower predicted moisture when using history dependent moisture uptake may mean that higher strength is retained by the adhesive after desorption. It is also interesting to note that while the residual moisture in Case II decreased after each desorption cycle, it either increased or remained the same in Case I. This is true for $1200 \mathrm{hrs}$ cycle as well as $2400 \mathrm{hrs}$ cycle and is a result of the constant diffusion coefficients and the use of $D_{1}$ for desorption in Case I. 


\section{Conclusions}

The experimental investigation of cyclic moisture diffusion showed that the absorption of moisture in the adhesive is a non-Fickian process and the rate of absorption varies with the moisture history of the adhesive. Desorption is a Fickian process, however, the rate of desorption increases with moisture cycling. $M_{\infty}$ increased because of moisture cycling. The observed change in the nature of the absorption and desorption processes with cycling indicates that the structure of the adhesive is changed by moisture absorption.

A comparison of moisture predictions based on diffusion parameters from a single absorption curve (Case I) and history dependent diffusion parameters (Case II) revealed that the amount of residual moisture predicted in Case I is always greater than Case II. If equilibrium is not reached during a cyclic situation, localised desorption and absorption processes occur in the adhesive layer and the use of the corresponding diffusion coefficients is necessary for a correct moisture prediction. Neglecting the moisture history dependent diffusion coefficient can result in over or under prediction of moisture during absorption. Since the diffusion rates in absorption and desorption are different and also have different dependencies on moisture history, it is necessary to use a methodology including moisture history for accurate prediction of degradation and residual joint strength of environmentally cycled adhesive joints. 


\section{REFERENCES}

[1] Hand, H.M., Arah, C.O., McNamara, D.K., and Mecklenburg, M.F., Int. J. Adhesion and Adhesives. 11, 15-23 (1991).

[2] Liljedahl, C.D.M., Crocombe, A.D., Wahab, M.A., and Ashcroft, I.A., The Journal of Adhesion. 82, 1061-1089 (2006).

[3] Minford, J.D., Handbook of Aluminum Bonding Technology and Data. (Marcel Dekker Inc, New York, 1993).

[4] Wahab, M.A., Ashcroft, I.A., Crocombe, A.D., and Shaw, S.J., The Journal of Adhesion. 77, 43-80 (2001).

[5] Brewis, D.M., Comyn, J., and Tredwell, S.T., Int. J. Adhesion and Adhesives. 7, 30-32 (1987).

[6] Masaro, L. and Zhu, X.X., Prog. Polym. Sci. 24, 731-775 (1999).

[7] Wilde, W.P.D. and Shopov, P.J., Composite Structures. 27, 243-252 (1994).

[8] Dewimille, B. and Bunsell, A.R., J. Phys. D: Appl. Phys. 15, 2079-2091 (1982).

[9] Popineau, S., Rondeau-Mouro, C., Sulpice-Gaillet, C., and Shahnahan, M.E.R., Polymer. 46, 10733-10740 (2005).

[10] Roy, S., Xu, W.X., Park, S.J., and Liechti, K.M., J Appl Mech. 67, 391-396 (2000).

[11] Loh, W.K., Crocombe, A.D., Wahab, M.A., and Ashcroft, I.A., Int. J. Adhesion and Adhesives. 25, 1-12 (2005).

[12] Wahab, M.A., D, C.A., Beevers, A., and Ebtehaj, K. (2002) Coupled stress diffusion analysis for durability study in adhesively bonded joints. Int. J. Adhesion and Adhesives Volume, 61-73

[13] Roy, S., J. Comp. Mater. 33, 1318-1342 (1999).

[14] Lin, Y.C. and Chen, X., Polymer. 46, 11994-12003 (2005).

[15] Cytec Engineered Materials, Datasheet - FM73 Toughened Epoxy Film. 1998.

[16] BS EN ISO 62:1999 Plastics - Determination of water absorption, British Standards Institution.

[17] Baker, A., Rose, F., and Jones, R., eds. Advances in the bonded composite repair of metallic aircraft structure. First ed. Vol. 1. 2002, Elsevier Science Ltd.

[18] De Neve, B. and Shanahan, M.E.R., Int. J. Adhesion and Adhesives. 12, 191-196 (1992).

[19] Mathcad 14 Help. 2007, Parametric Technology Corporation. 
[20] Liljedahl, C.D.M., Crocombe, A.D., Wahab, M.A., and Ashcroft, I.A., Int. J. Adhesion and Adhesives. 27, 505-518 (2007).

[21] Hua, Y., Crocombe, A.D., Wahab, M.A., and Ashcroft, I.A., The Journal of Adhesion. 82, 135-160 (2006).

[22] Crocombe, A.D., Hua, Y., Loh, W.K., Wahab, M.A., and Ashcroft, I.A., Int. J. Adhesion and Adhesives. 26, 325-336 (2006).

[23] Crank, J., The Mathematics of Diffusion. (Clarendon Press, Oxford, 1975). 2nd ed.

[24] Carter, F.G. and Kibler, K.G., J. Comp. Mater. 12, 118-131 (1978).

[25] Adamson, M.J., J. Mat. Sci. 15, 1736-1745 (1980). 


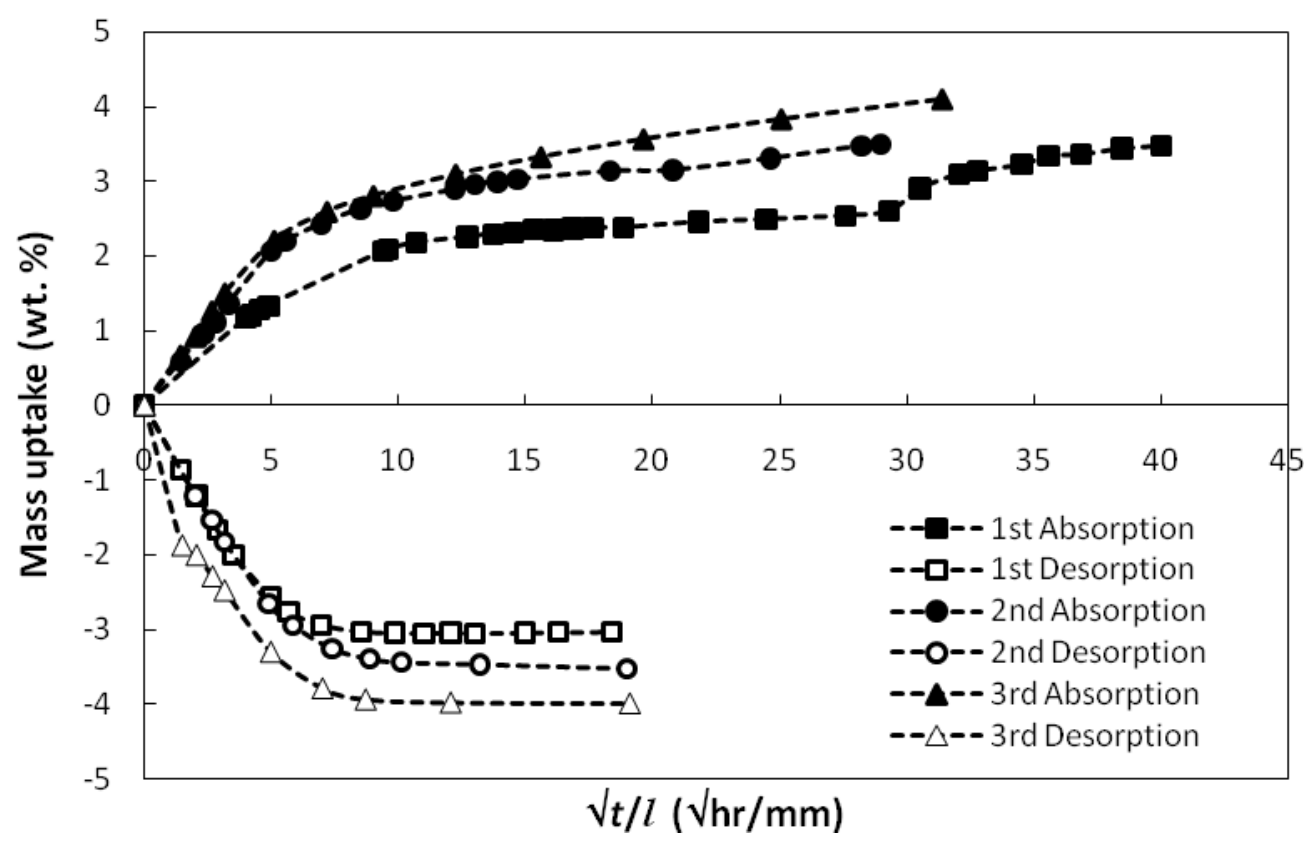

(a)

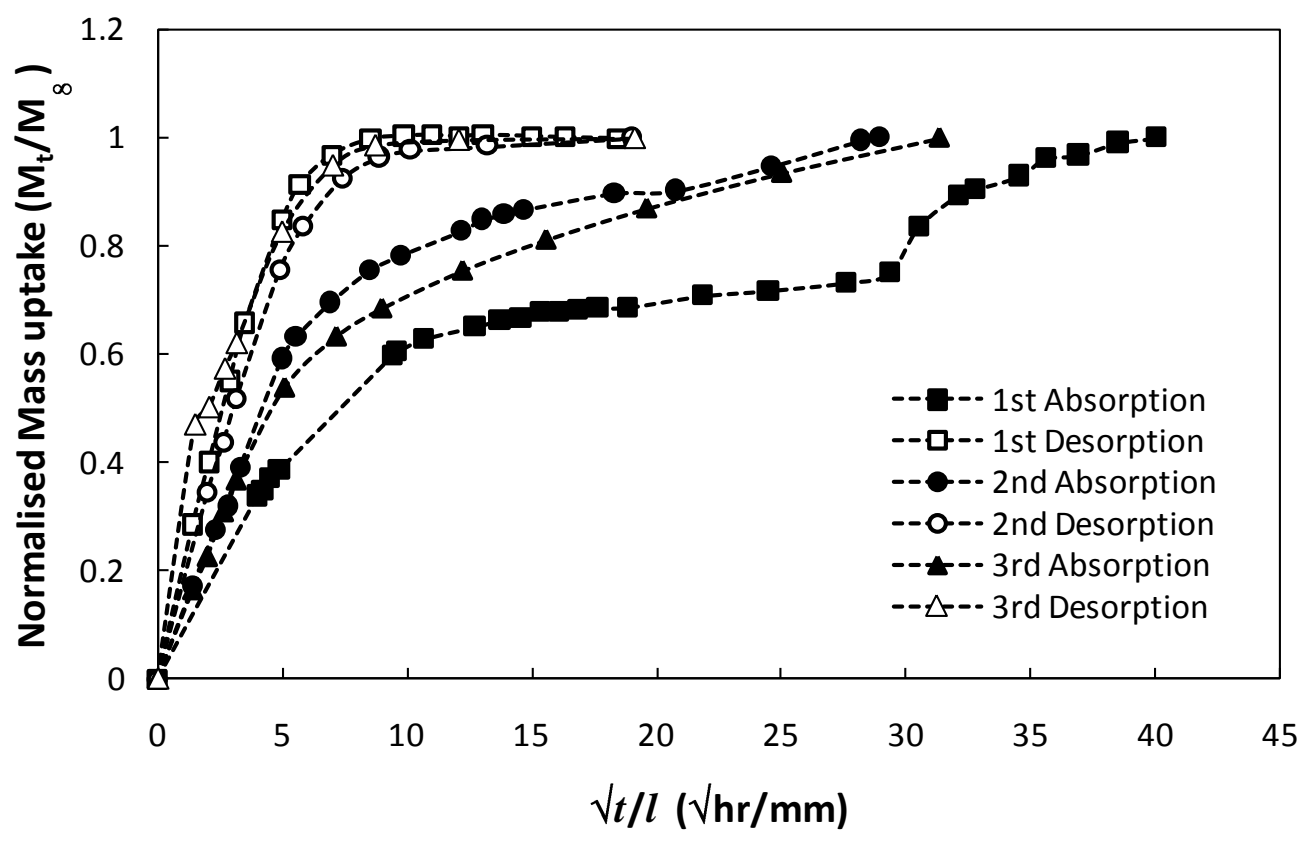

(b)

Figure 1: Moisture absorption and desorption curves for $1 \mathrm{~mm}$ thick FM73 bulk adhesive when conditioned at $50^{\circ} \mathrm{C}$, immersed in water (a) mass uptake by wt $\%$ (b) normalised mass uptake. 


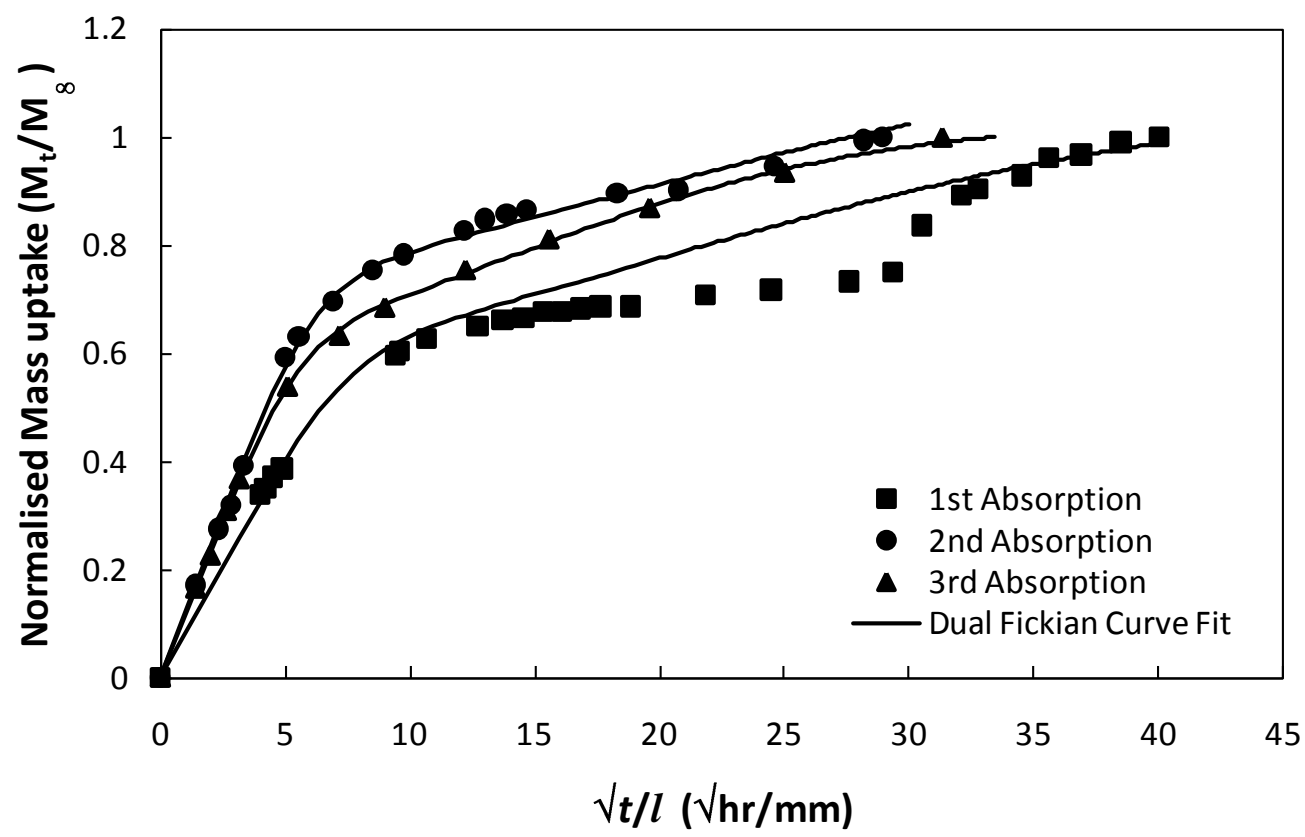

(a)

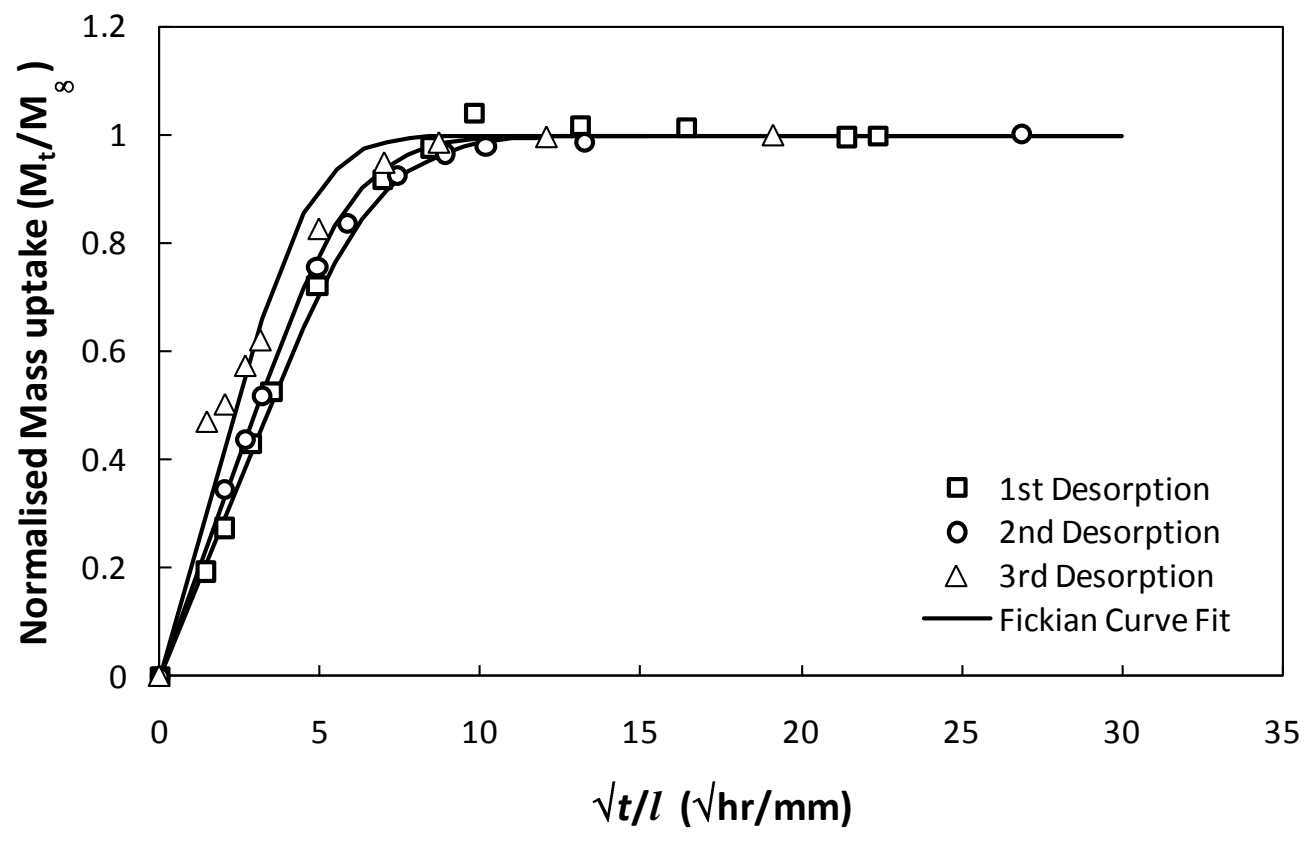

(b)

Figure 2: Curve fits of experimental moisture uptake for $1 \mathrm{~mm}$ thick samples when conditioned at $50^{\circ} \mathrm{C}$, immersed in water (a) absorption (b) desorption. 


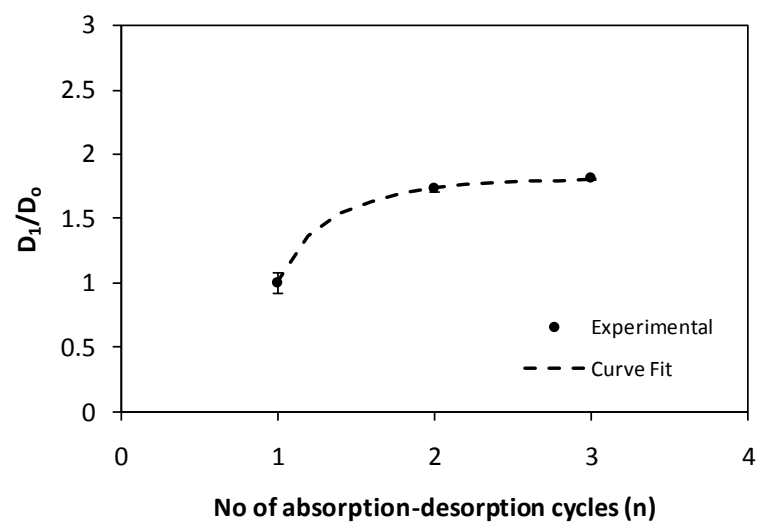

(a)

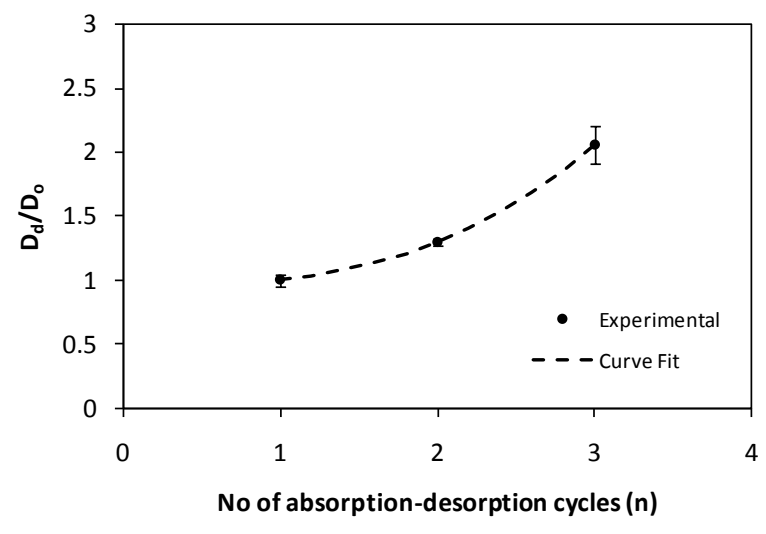

(c)

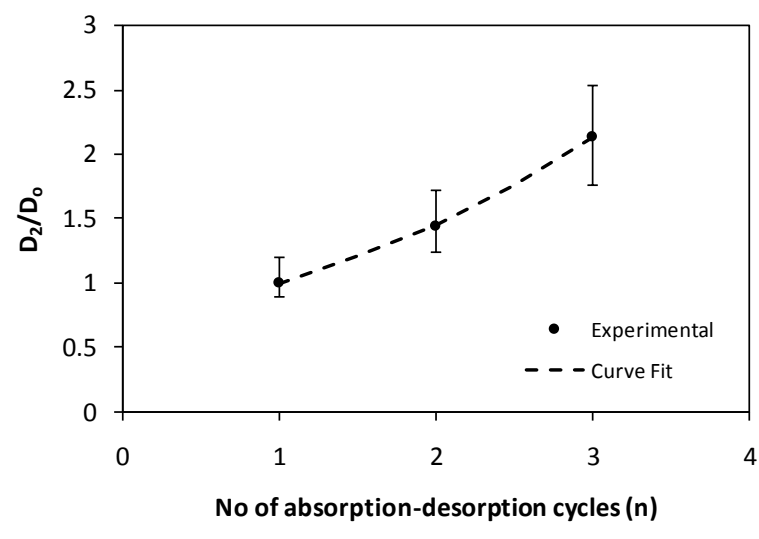

(b)

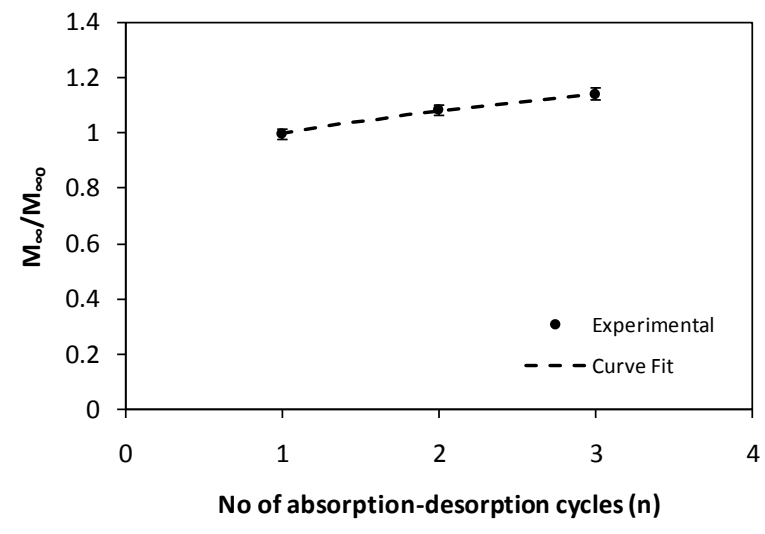

(d)

Figure 3: Changes in moisture diffusion characteristics for FM73 over multiple absorption-desorption cycles (a) $D_{1}$ (b) $D_{2}$ (c) $D_{d}$ (d) $M_{\infty}$. 


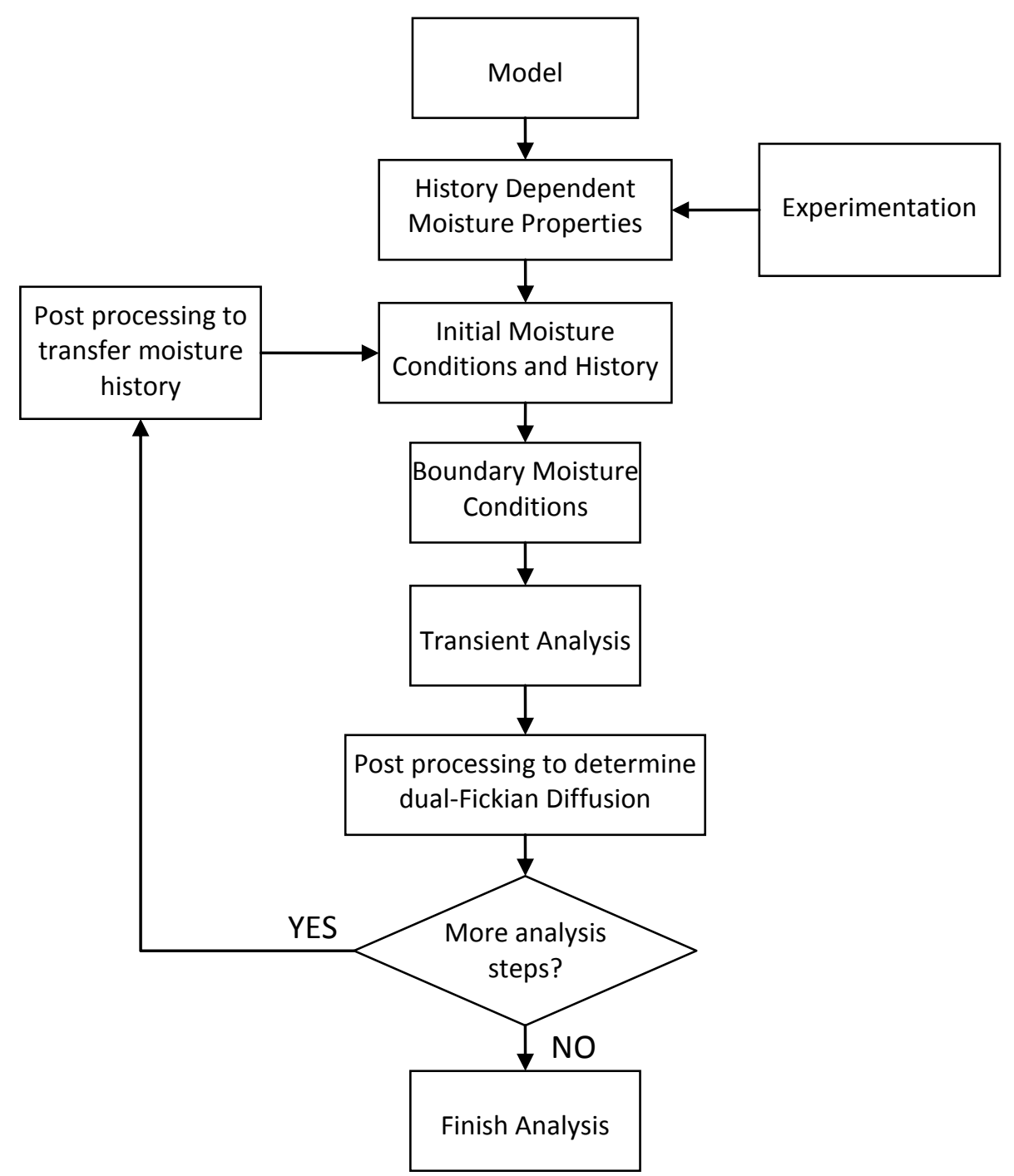

Figure 4: Methodology for modelling cyclic moisture diffusion. 


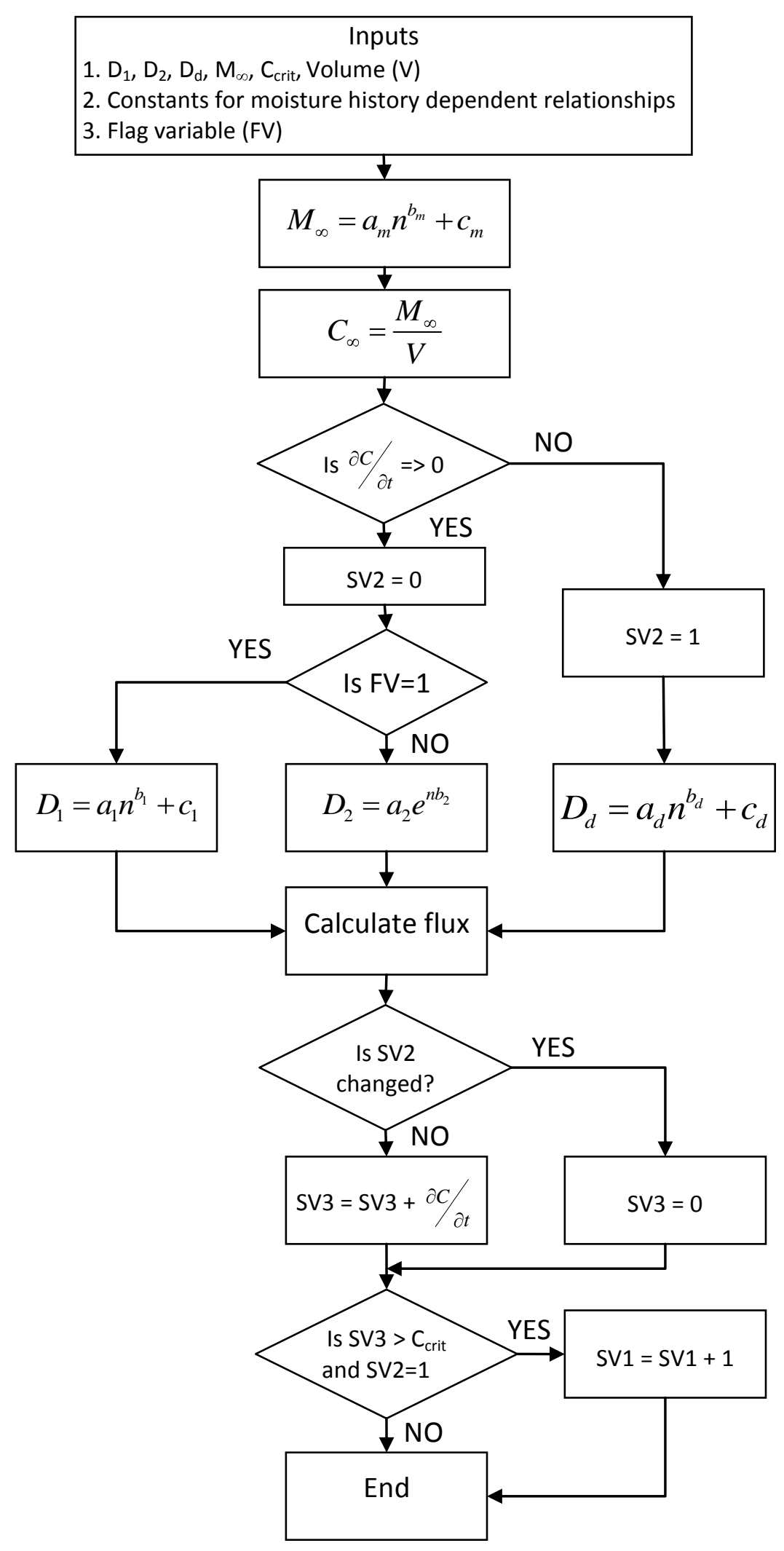

Figure 5: Structure of user defined material subroutine UMATHT. 


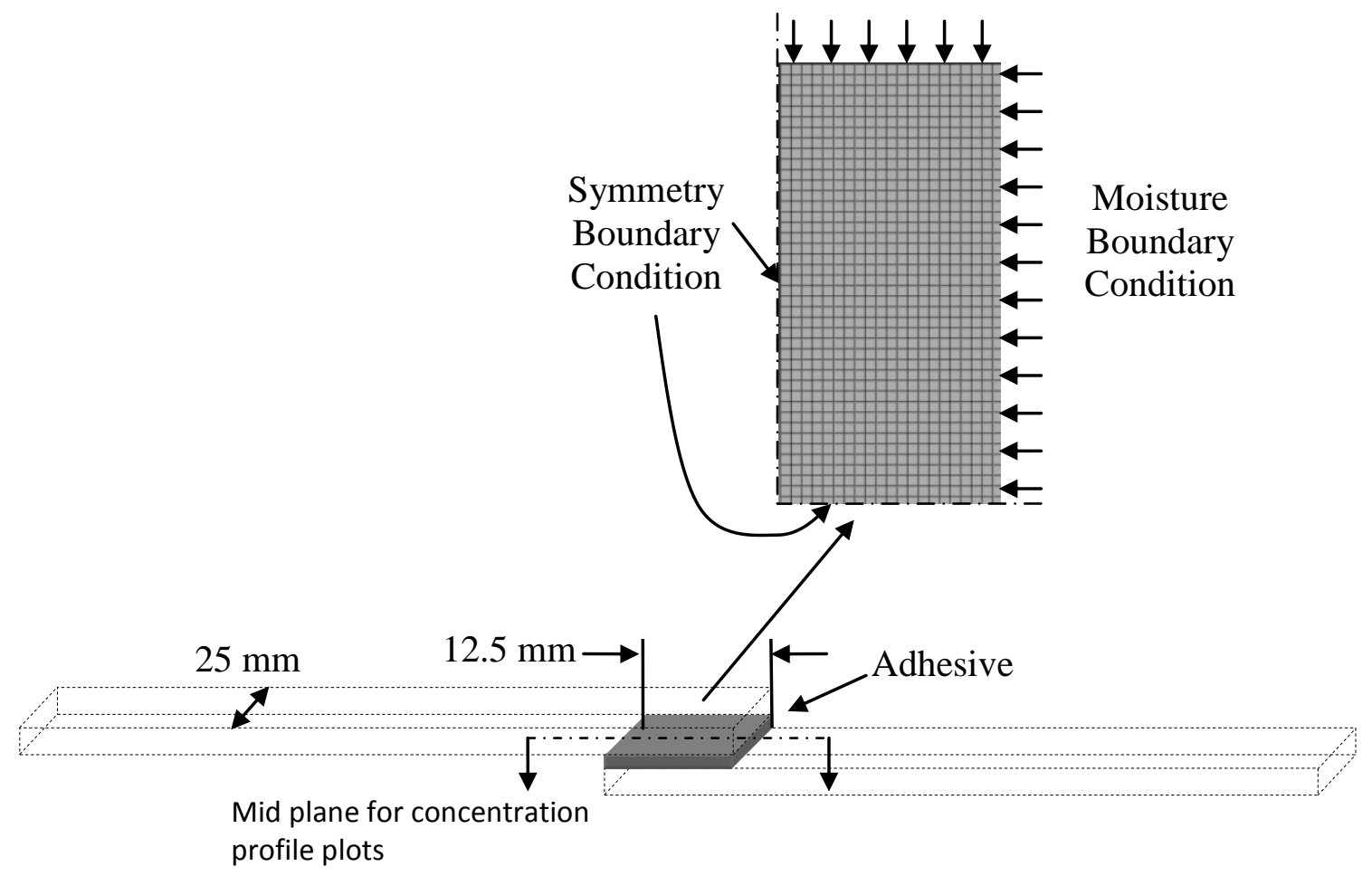

Figure 6: Single lap joint geometry with finite element mesh of the adhesive layer used for modelling the cyclic moisture diffusion.

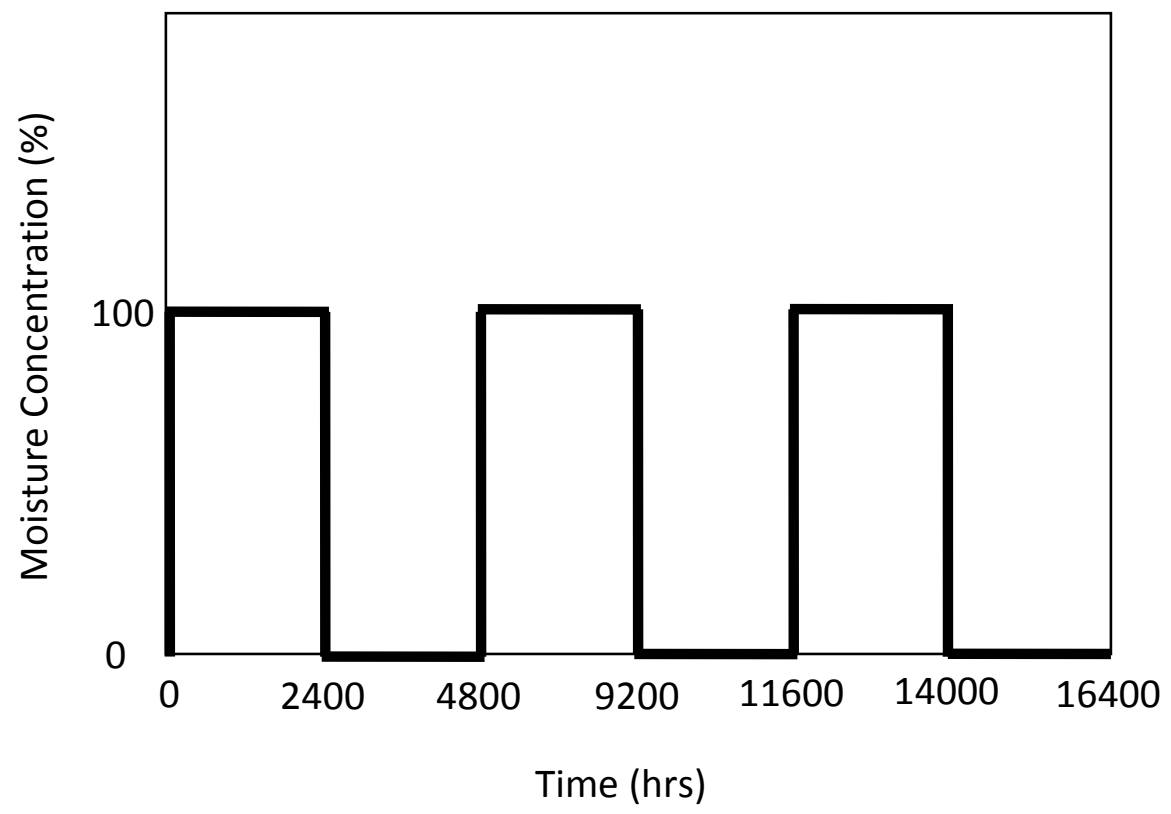

Figure 7: Cyclic moisture conditioning environment for finite element modelling. 


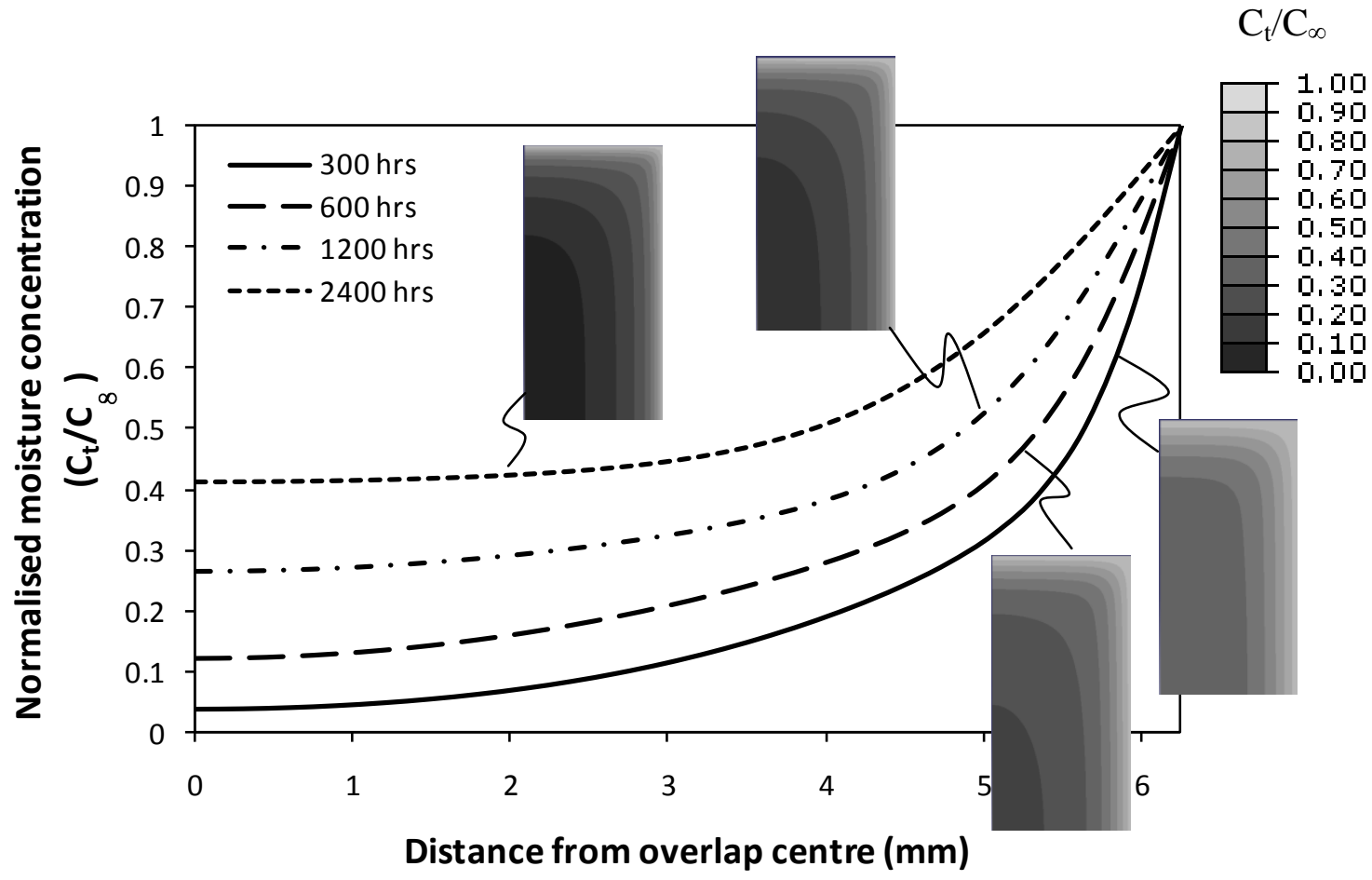

Figure 8: Moisture concentration in the adhesive layer after first absorption cycle.

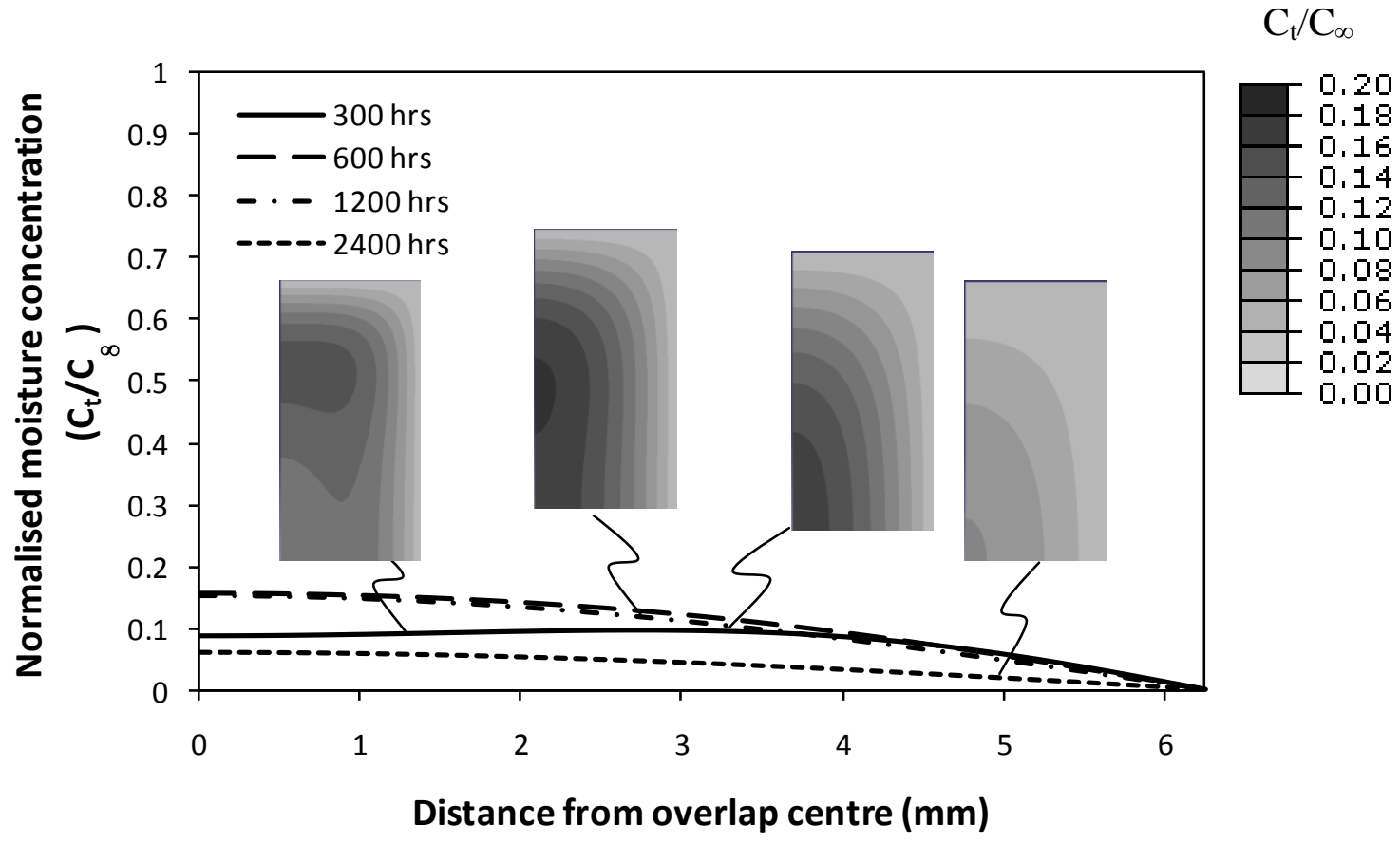

Figure 9: Moisture concentration in the adhesive layer after first desorption cycle. 

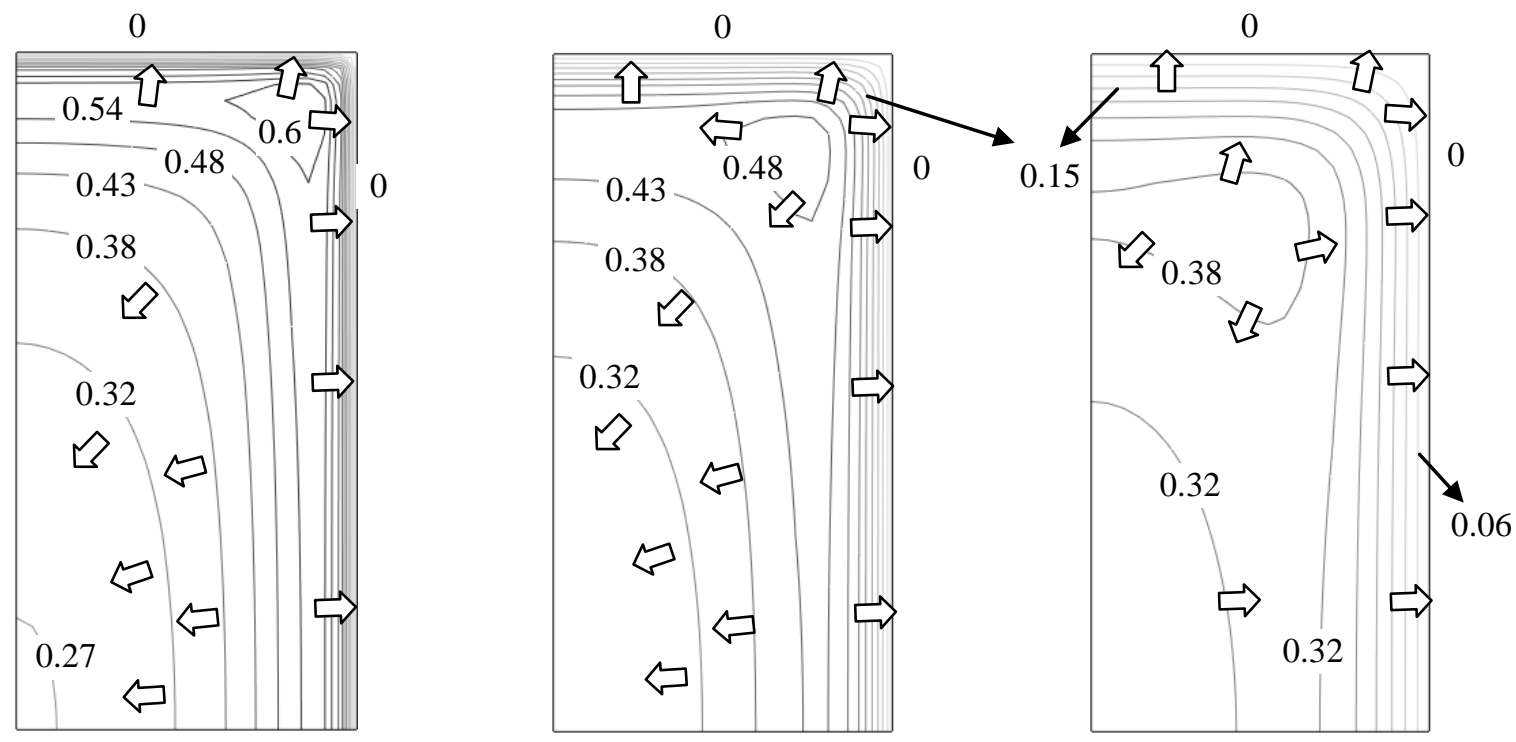

Figure 10: Contour plots of normalised moisture concentration in the adhesive layer during a typical desorption process. High localised concentration causes simultaneous absorption and desorption in the adhesive layer. Arrows indicate direction of moisture transport. 


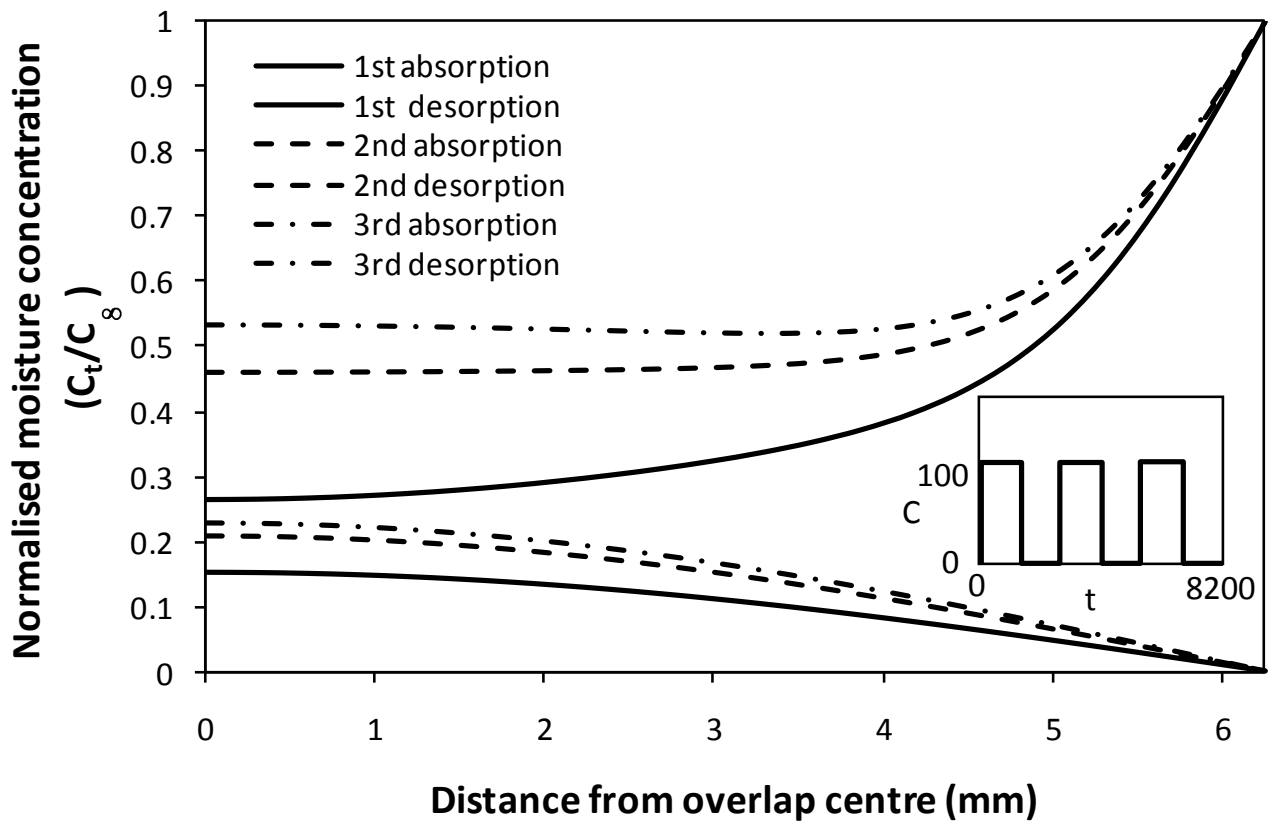

Figure 11: Moisture concentration in the adhesive layer after absorption-desorption cycles of 1200 hrs each.

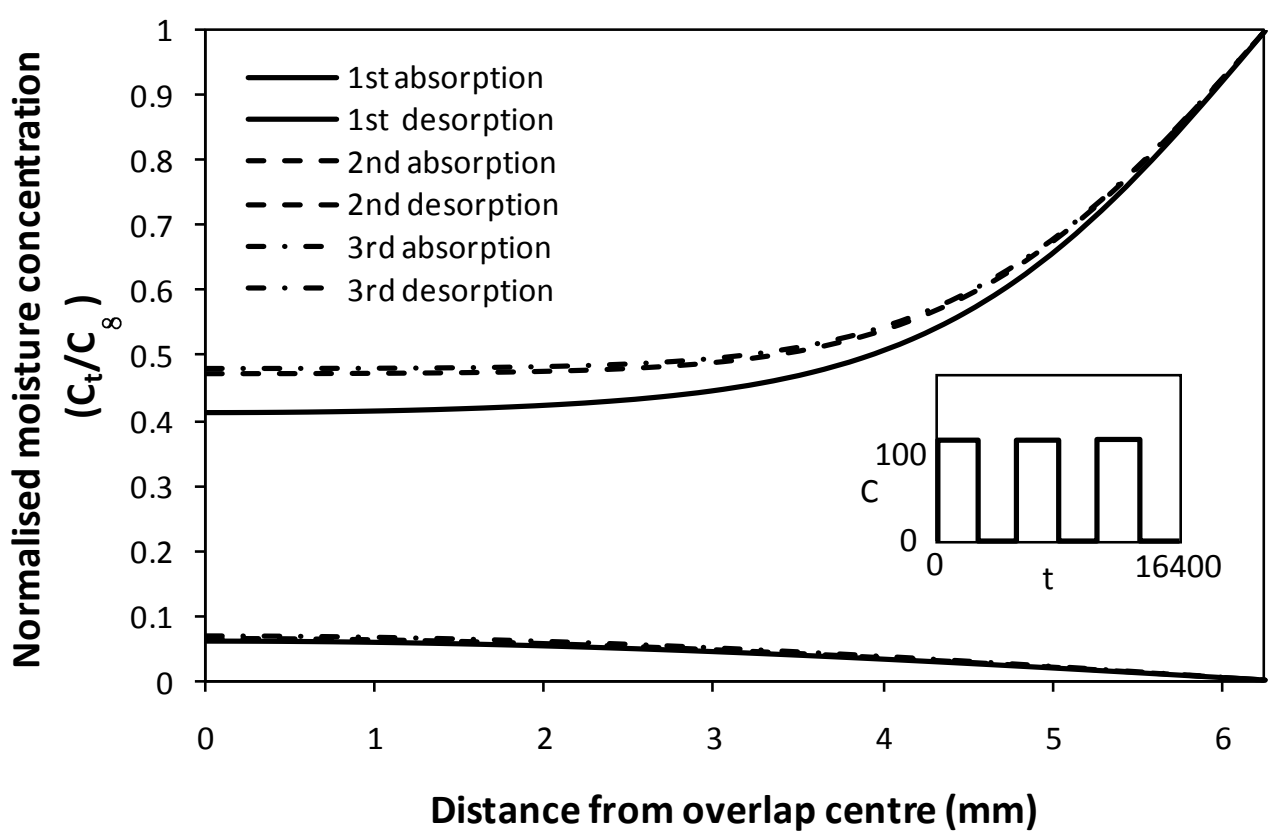

Figure 12: Moisture concentration in the adhesive layer after absorption-desorption cycles of 2400 hrs each. 


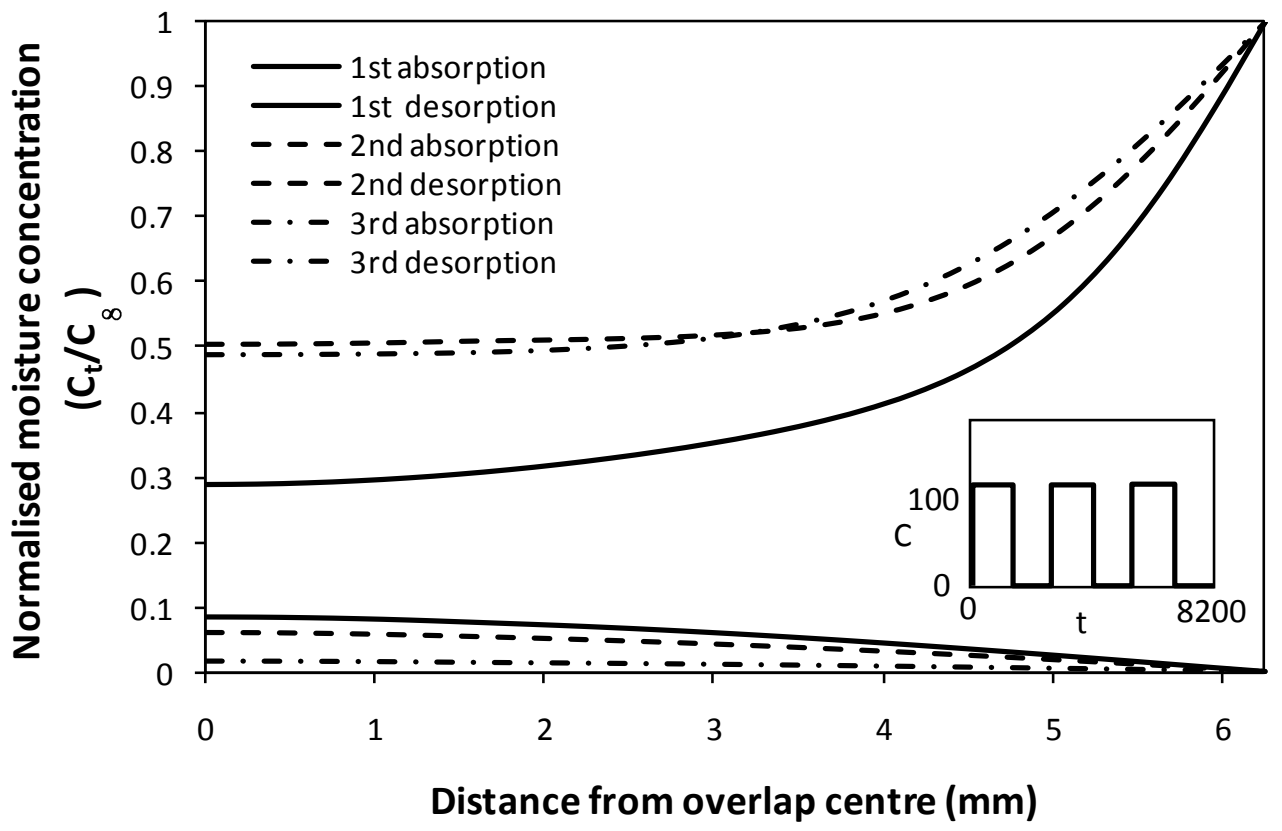

Figure 13: Moisture concentration in the adhesive layer, using multi-cycle model, after absorption-desorption cycles of 1200 hrs each.

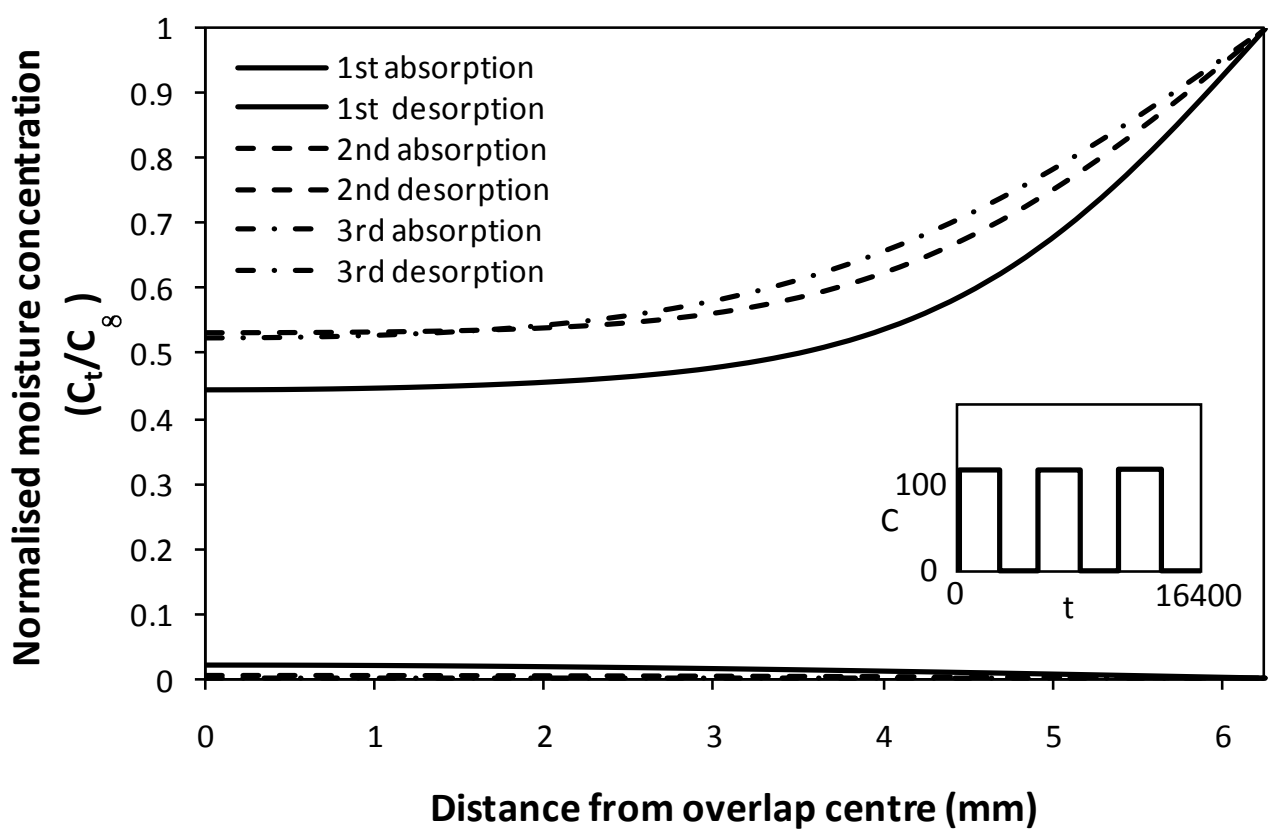

Figure 14: Moisture concentration in the adhesive layer, using multi-cycle model, after absorption-desorption cycles of 2400 hrs each. 


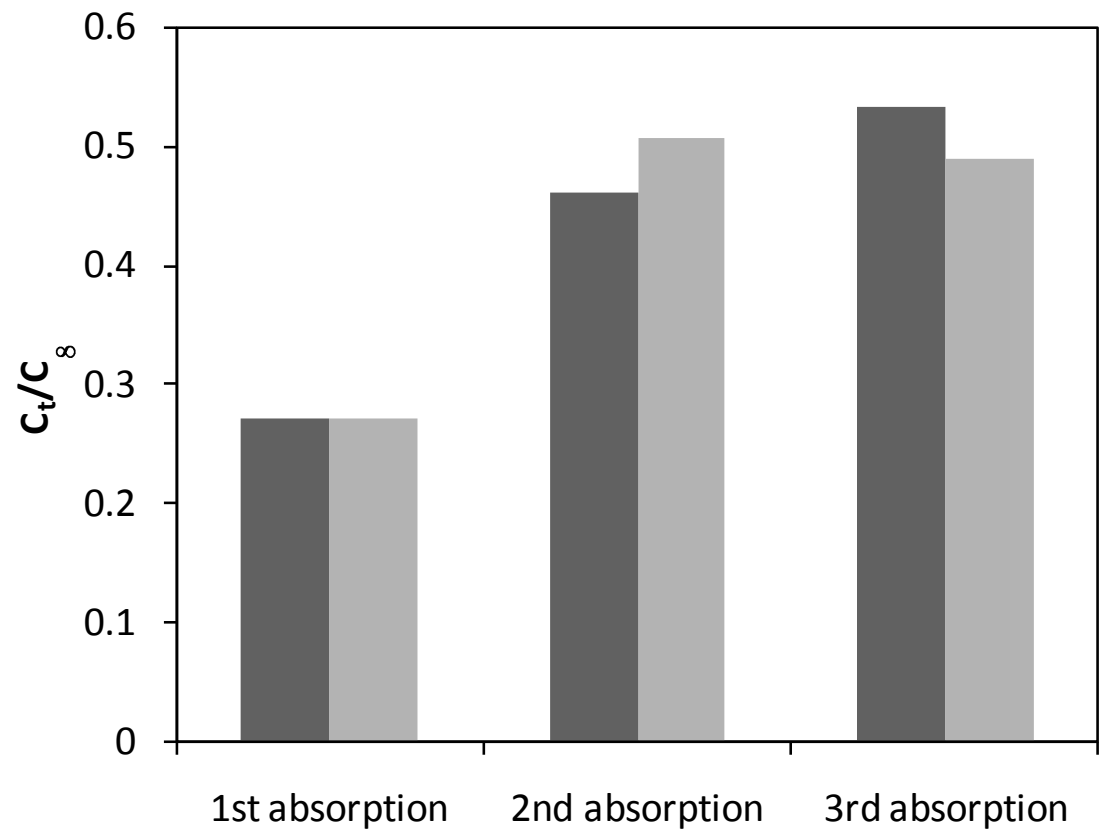

Case I

Case II

(a)

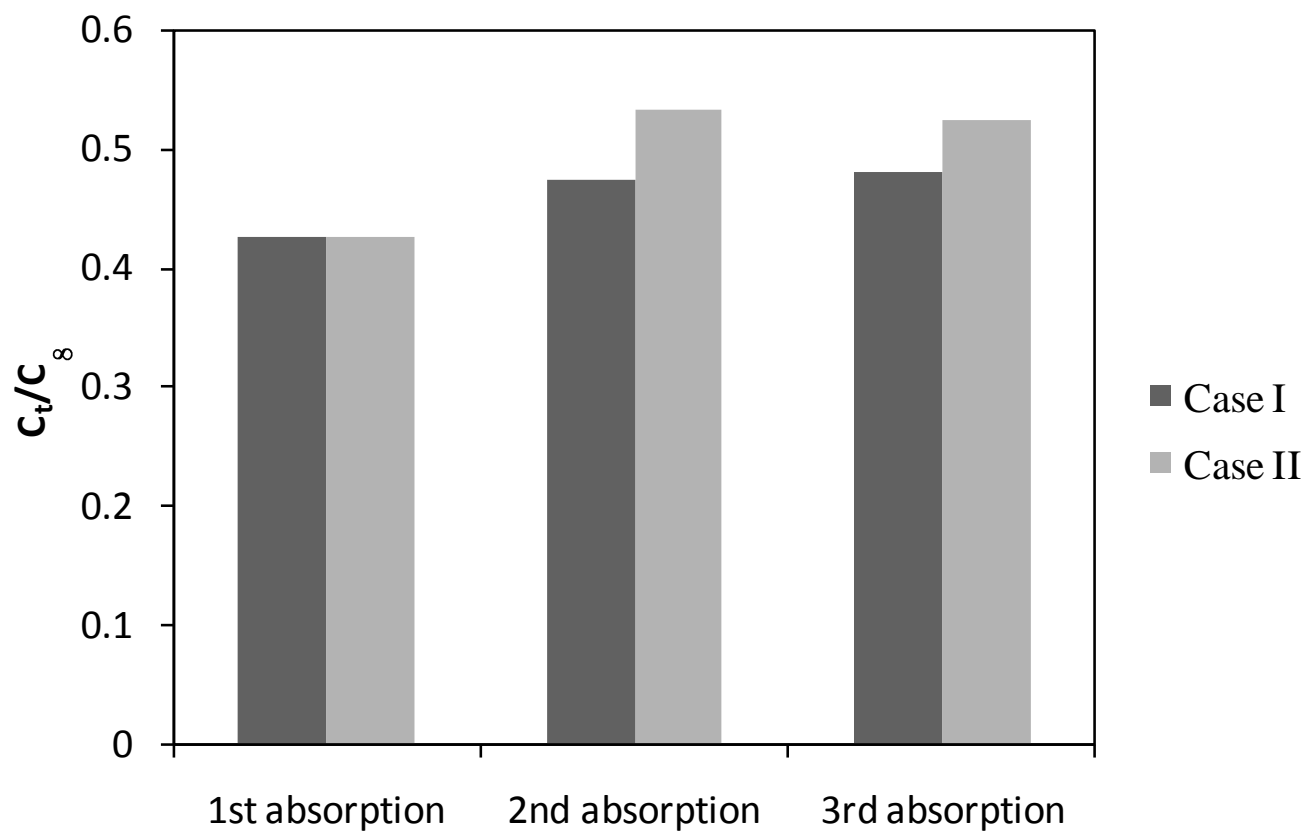

(b)

Figure 15: Normalised moisture concentration at the overlap centre after absorption for (a) $1200 \mathrm{hr}$ (b) $2400 \mathrm{hr}$ conditioning. 


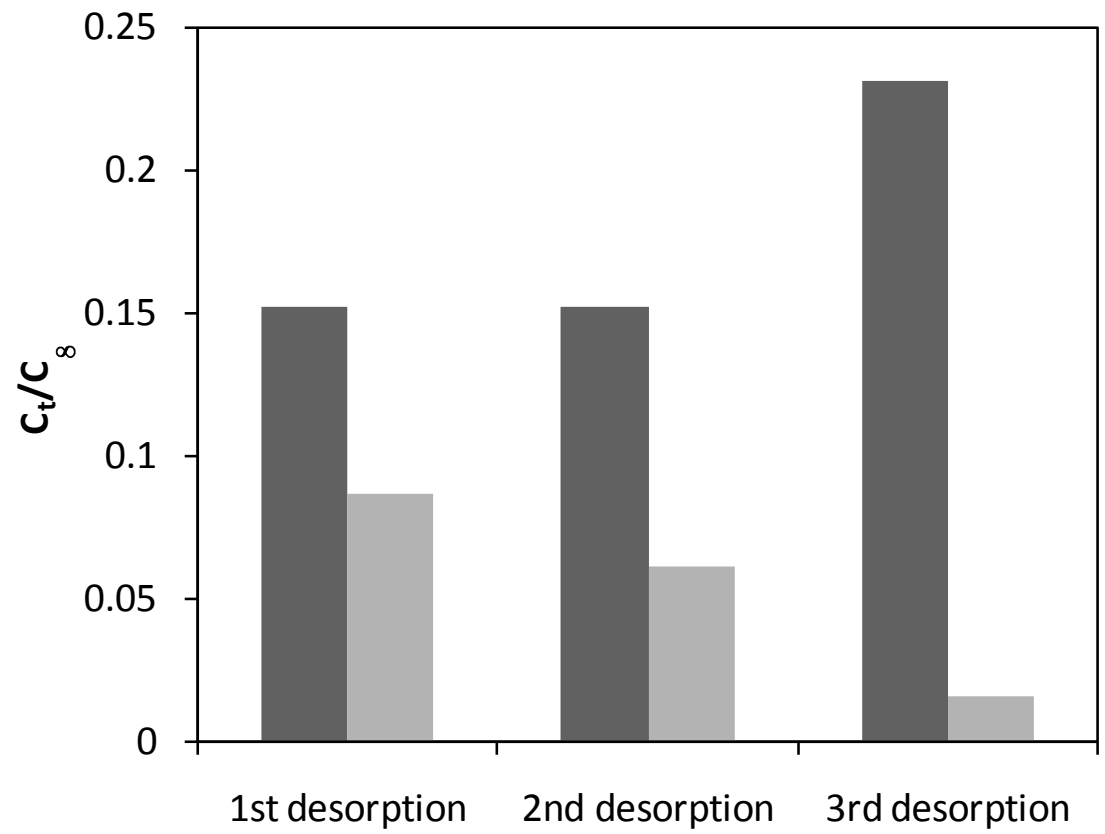

Case I

Case II

(a)

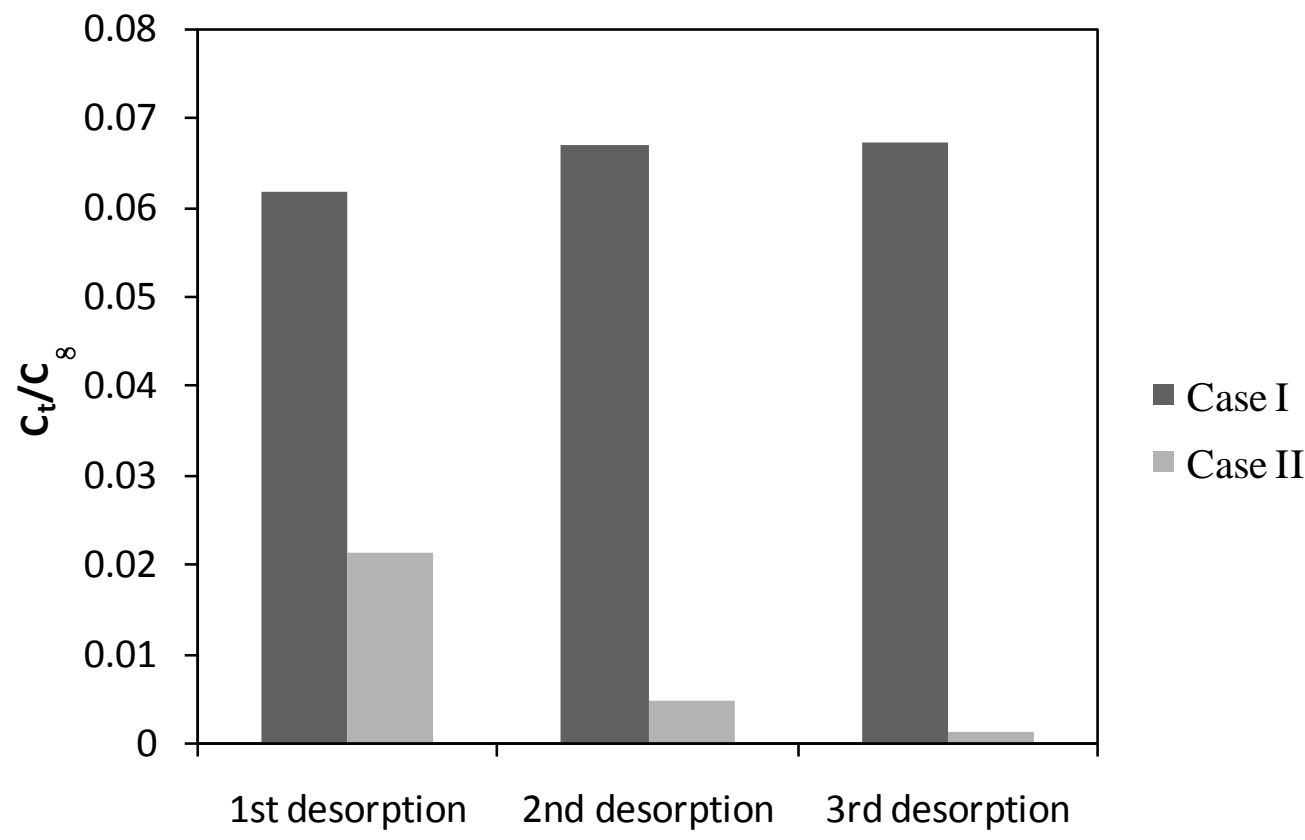

(b)

Figure 16: Normalised moisture concentration at the overlap centre after desorption for (a) $1200 \mathrm{hr}$ (b) $2400 \mathrm{hr}$ conditioning. 
Table 1: Coefficients of dual Fickian model determined by curve fitting to absorption data.

\begin{tabular}{|l|c|c|c|c|}
\hline \multicolumn{1}{|c|}{ Diffusion Cycle } & $\begin{array}{c}D_{1} \\
\mathrm{~mm}^{2} / \mathrm{hr}\end{array}$ & $\begin{array}{c}D_{2} \\
\mathrm{~mm}^{2} / \mathrm{hr}\end{array}$ & $\begin{array}{c}M_{1 \infty} \\
\mathrm{wt} \%\end{array}$ & $\begin{array}{l}M_{2 \infty} \\
\mathrm{wt} \%\end{array}$ \\
\hline $1^{\text {st }}$ Absorption & 0.014 & 0.0004476 & 1.78 & 1.92 \\
\hline $2^{\text {nd }}$ Absorption & 0.024 & 0.0006459 & 2.32 & 1.68 \\
\hline $3^{\text {rd }}$ Absorption & 0.025 & 0.0009552 & 2.23 & 1.97 \\
\hline
\end{tabular}

Table 2: Coefficients of Fickian model determined by curve fitting to desorption data.

\begin{tabular}{|l|c|c|}
\hline \multicolumn{1}{|c|}{ Diffusion Cycle } & $\begin{array}{c}D_{d} \\
\mathrm{~mm}^{2} / \mathrm{hr}\end{array}$ & $\begin{array}{c}M_{\infty} \\
\mathrm{wt} \%\end{array}$ \\
\hline $1^{\text {st }}$ Desorption & 0.017 & 3.7 \\
\hline $2^{\text {nd }}$ Desorption & 0.025 & 4.0 \\
\hline $3^{\text {rd }}$ Desorption & 0.035 & 4.2 \\
\hline
\end{tabular}

Table 3: Constants obtained by curve fitting for empirical diffusion characteristic functions.

\begin{tabular}{|l|c|c|c|}
\hline Diffusion Variable & $a$ & $b$ & $c$ \\
\hline$D_{1}$ & -0.8321 & -3.056 & 1.832 \\
\hline$D_{d}$ & 0.0451 & 2.912 & 0.9549 \\
\hline$M_{\infty}$ & 0.2144 & 0.4574 & 0.7856 \\
\hline \multicolumn{4}{|c|}{} \\
\hline \multicolumn{4}{|c|}{$x$} \\
\hline$D_{2}$ & 0.677 & 0.3814 & \\
\hline
\end{tabular}

